\title{
Examining the Interplay Between Big Data and Microservices - A Bibliometric Review
}

\author{
Daniel Staegemann ${ }^{1 *}$, Matthias Volk ${ }^{1}$, Aamir Shakir ${ }^{1}$, \\ Erik Lautenschläger ${ }^{2}$, and Klaus Turowski ${ }^{1}$ \\ ${ }^{1}$ Otto von Guericke University, Universitätsplatz 2, Magdeburg, 39104, Germany \\ ${ }^{2}$ FernUniversität in Hagen, Universitätsstraße 11, Hagen, 58097, Germany \\ daniel.staegemann@ovgu.de, matthias.volk@ovgu.de, shakir@ovgu.de, \\ erik.laute@gmail.com, klaus.turowski@ovgu.de
}

\begin{abstract}
Due to the ever increasing amount of data that is produced and captured in today's world, the concept of big data has risen to prominence. However, implementing the respective applications is still a challenging task. This holds especially true, since a high degree of flexibility is desirable. One potential approach is the utilization of novel decentralized technologies, as in the case of microservices to construct such big data analytics solutions. To obtain an overview of the current situation regarding the corresponding research, using the scientific database Scopus and its provided tools for search and analytics, this bibliometric review provides an analysis of the literature and subsequently discusses avenues for future research.
\end{abstract}

Keywords: Big Data, Microservice, Big Data Engineering, Bibliometric Review, Literature Review.

\section{Introduction}

The world of today is influenced by an ongoing increase in the amount of data [1], [2] that are created, captured, stored and analyzed [3]. Furthermore, also the demand for the corresponding processing speed increases [4]. As a consequence of those developments, the conventional technologies and methods of data handling are more and more often no longer sufficient, resulting in the necessity for a development of new techniques and the establishment of modern data analysis paradigms, as they are constituted by the terms big data and big data analytics (BDA) [5], [6]. Organizations who build the respective capabilities to utilize this new source of insights can hereby enhance their performance [7] through, inter alia, a more accurate or faster decision making, cost reductions, an optimization of their offered portfolio of services or an improvement of customer acquisition and retention [8]-[10].

\footnotetext{
* Corresponding author
}

(C) 2021 Daniel Staegemann, Matthias Volk, Aamir Shakir, Erik Lautenschläger, and Klaus Turowski. This is an open access article licensed under the Creative Commons Attribution License (http://creativecommons.org/licenses/by/4.0).

Reference: D. Staegemann, M. Volk, A. Shakir, E. Lautenschläger, and K. Turowski, "Examining the Interplay Between Big Data and Microservices - A Bibliometric Review," Complex Systems Informatics and Modeling Quarterly, CSIMQ, no. 27, pp. 87-118, 2021. Available: https://doi.org/10.7250/csimq.2021-27.04

Additional information. Author ORCID iD: D. Staegemann - https://orcid.org/0000-0001-9957-1003 and M. Volk https://orcid.org/0000-0002-4835-919X. PII S225599222100157X. Received: 9 February 2021. Accepted: 29 July 2021. Available online: 30 July 2021. 
However, implementing the respective applications is still a challenging task [11], [12]. This is even exacerbated by the circumstance that the business reality, including, for instance, the accessible sources, available algorithms and technologies as well as the type of questions whose answers promise benefit to the organization, might evolve over time, which also requires the BDA to adapt accordingly. As a result, a modular design, in contrast to a monolithic architecture, could be desirable [13]. One potential approach to achieve said modularity is the utilization of microservices as building blocks of the BDA solution as a whole [14]-[16].

Yet, while there are publications that deal with the interplay of big data and microservices, to our knowledge, there is no comprehensive overview of the development of this research as a whole, even though such studies can provide valuable insights by identifying trends as well as potential future research avenues and demands. This review aims to bridge this gap by answering the following research questions:

RQ1: What is the current situation in the research combining big data and microservices?

RQ2: Which are potential research areas or directions to facilitate the interconnected use of microservices and big data?

To address the research questions, the literature on big data and microservices is analyzed through conducting a bibliometric review on these topics using the search engine of Scopus ${ }^{1}$.

The remainder of this article is structured as follows. In the background (Section 2), the topics "big data" and "microservices" are briefly outlined. Afterward, the article's methodology is explained (Section 3), followed by the presentation and discussion of the search's findings (Section 4). Finally, in Section 5, a conclusion is given, also highlighting potentially beneficial directions for future research.

\section{Background}

In this section, the concepts of big data and microservices are briefly outlined, providing a general understanding before the actual review is conducted.

\subsection{Big Data}

For more than a decade, the term "big data" underwent a remarkable evolution. While initially being referred to as a synonym for large amounts of data that cannot be easily handled by relational databases and technologies of that time, today it covers a variety of advanced data characteristics, technologies, paradigms and methods [17]. During this time, the concept has undergone significant changes that dramatically moved the term from a hype topic [18] to the foundation of most of the data-driven and data-intensive projects known today [12]. Hence, it is not surprising that a multitude of researchers and practitioners are harnessing big data in all its facets within their endeavors, as in prominent application areas, such as healthcare [19], [20], transportation [21] or tourism [22].

Despite that long-lasting maturation and a highly active research community [23], no distinct and universally applied definition was found that precisely describes the nature and elements of that term [17]. Notwithstanding that, according to one of the most widely used definitions, big data "consists of extensive datasets - primarily in the characteristics of volume, variety, velocity, and/or variability - that require a scalable architecture for efficient storage, manipulation, and analysis" [24]. Similar to the pure definition itself, many differences about the description of the data exist. While some of the data characteristics are observed as core characteristics, namely, volume, variety, and velocity, others are treated unequally [17], [25]. While volume refers to the size and the number of elements to be processed, the variety focuses on the structure of data, which can be either unstructured, semi-structured or structured. Furthermore, the velocity

\footnotetext{
${ }^{1}$ Www.scopus.com
} 
describes the speed at which the data is coming in and is being processed [6]. Lastly, the variability that was addressed in the aforementioned definition refers to changes which may occur in the dataset, regarding the other characteristics [24].

Although eventually this may give rise to the feeling that the engineering, testing, and application of related systems became easier in recent years, the opposite is often the case. As stated before, various challenges are still existing that hamper the related implementation and deployment activities. Apart from the pure lack of experts and qualified staff [26], the comprehensive planning, engineering, and integration of architectures represent a cumbersome task [11]. Many practitioners and researchers noted this problematic situation and attempted to reduce the prevailing complexity through the design and development of promising solutions, such as reference architectures [27], decision support systems [28], automation approaches [29] or the application of new technologies [15]. Especially in times in which highly decentralized or loosely coupled environments are sought after more than ever, as in the case of very large business application scenarios, the use of big data in combination with such environments remains desirable. Microservice technologies, in this direction, constitute a promising approach.

\subsection{Microservices}

Even though there seems to be no widely recognized definition of the term "microservice", it can be described as an architectural approach to building software applications and a relatively new implementation of service-oriented architecture [30]. In essence, it entails the development of a single application by decomposing it into a suit of small services [31, p.6] where each of them runs in their own process and communicates with other applications only via lightweight mechanisms. Furthermore, these services, as for their independent nature, usually only need a rather limited amount of central management [32] and can be written in differing programming languages and are based on different technology stacks [15], which can, for instance, be specialized on analysis, management tasks or data storage functionalities.

This setup allows them to be efficiently deployed independently of each other with continuous deployment tools and pipelines, and it is a common practice that they are based on business functions, so a service can be specialized to solve one related task. This structure has diverse practical and organizational implications. The microservice approach tends to align teams around business capabilities instead of traditionally building teams based on the technology layer. Consequently, the teams are more cross-functional and encompass the full range of skills required for development, thus, preventing a plethora of siloed architectures that each contain their own logic [33]. The approach comes with the constraint that the team implementing this concept is usually not based around strict hierarchical communication [34].

In general, componentization is considered to be a good practice in software engineering, but achieving a high degree of modularity is often seen as a difficult task [35]. As systems are broken down into services that are independently deployable, with the microservice architecture, componentization is achieved by design. One of the major advantages is the reduced effort for maintenance and modifications. For small internal changes, often only the affected service has to be redeployed. This also facilitates an evolutionary design, where the services' decomposition is used as a driving force to enable frequent and controlled changes in the system [36]. As microservices are specialized around the business logic, minor changes or feature requests can lead to implementing completely new services or variants of existing ones, which, in both cases, can be easily integrated with the existing application. Additionally it allows to adopt to new technologies on a smaller scale first. In theory, when completely following the promoted idea, every microservice has its own storage and its own technology to manage its stored data. However, since this approach would often be highly unpractical, in many cases central databases are used, provided the services are still not sharing data and each only accesses its respective section [31, pp. 81-84]. 


\section{Methodology}

This study is heavily inspired by and somewhat follows the approach used in [37], which, in turn, refers to [38] and [39]. However, the incorporation of additional steps for filtering as well as the use of inclusion and exclusion criteria, as propagated in [40], amends the approach of [37] and helps in increasing the overall quality. To assure even more rigor and despite the study not being a structured literature review, but a bibliometric review, the steps proposed by Kitchenham et al. [41] for conducting a structured literature review have been mostly adapted but slightly modified when needed, as also has been practiced, for instance, in [42]. At first, the research questions that are being investigated are formulated. Afterwards, the search string is defined and used to obtain the initial set of literature. By using certain inclusion and exclusion criteria, it is reduced to only those publications that are actually suitable for the study's scope. In a fourth step, the relevant data from the remaining papers are collected. Those are subsequently analyzed and presented. Finally, the study's results are being interpreted to generate additional insights that exceed pure numerical information, identify trends, shortcomings and avenues for future research (based on the most influential publications), and help to advance the domain as a whole. Those six steps conducted in this review are outlined in Table 1. However, while the first four steps are executed one by one, the presentation of the results in the fifth step is already complemented with the corresponding interpretations to keep the context.

Table 1. Methodology

\begin{tabular}{|c|l|l|}
\hline Number & Step & Description \\
\hline 1 & Research questions & Formulate the questions that are being investigated \\
\hline 2 & Search process & Define and use search term to find initial set of literature \\
\hline 3 & Inclusion and exclusion criteria & Filter the literature \\
\hline 4 & Data collection & Extract relevant data from the remaining publications \\
\hline 5 & Data analysis & Present the results \\
\hline 6 & Interpretation & Interpret the results to generate additional insights \\
\hline
\end{tabular}

Since the research questions have already been defined in the first section, subsequently, in the following, the actual search process takes place.

As it is common for papers that are focused on analyzing the existing literature [43], [44], the most important step is the initial search for relevant literature by defining a suitable search string that includes the relevant papers, without being too broad, and thereby diluting the relevance of the findings.

To find the relevant literature, at first, a search was conducted in Scopus, using the following search string:

\section{TITLE-ABS-KEY ("big data") AND TITLE-ABS-KEY ( microservice OR microservices OR "micro service" OR "micro services" OR "micro-service" OR "micro-services" )}

This means that it was searched for all those papers whose title, abstract or keywords contain the terms big data and at least one of microservice, microservices, micro service, micro services, micro-service or micro-services. The latter is necessary to avoid missing relevant publications due to possible variants in the spelling. Furthermore, with Scopus being considered the most extensive abstract and citation database for scientific literature like conference proceedings, scientific books and journals and a variety of tools to facilitate sophisticated searches [37], [45], its results promise a comprehensive overview of the domain of interest.

The search was conducted on 27.06.2021. In doing so, 243 entries, matching the search term, where found. Those are distributed between five types of publications, as shown in Table 2 . 
Table 2. Distribution of publications by type

\begin{tabular}{|l|r|r|}
\hline Type & Number & Percentage \\
\hline Conference Paper & 171 & $70.37 \%$ \\
\hline Article & 34 & $13.99 \%$ \\
\hline Conference Review & 33 & $13.58 \%$ \\
\hline Book Chapter & 4 & $1.65 \%$ \\
\hline Review & 1 & $0.41 \%$ \\
\hline Total & 243 & $100.00 \%$ \\
\hline
\end{tabular}

Searching for non-unique items (i.e., identical title) revealed three occurrences, resulting in their removal. While two of those three are not complete duplicates but updates to older papers [46], [47], the deprecated versions were still excluded, leaving only the newer ones. Therefore, the set of publications considered for the actual analysis comprises 240 entries.

After getting an overview of those papers, it became apparent, that the entries in the category "Conference Review" were of no benefit, since they have no scientific content of their own but are actually just outlining conferences, respectively their proceedings. As a result, items of this type have been excluded for the remainder of this study. Furthermore, only contributions for which the publication process has been finalized were being considered. Subsequently, two additional papers have been excluded. Finally, also papers which were not written in English have been excluded, eliminating two more contributions. Applying all of those criteria brings the final number of considered publications down to 205. To increase transparency and allow other researchers to understand and replicate the conducted steps, as, for instance, heavily advocated for in [48], the entire filter process is broken down in Figure 1.

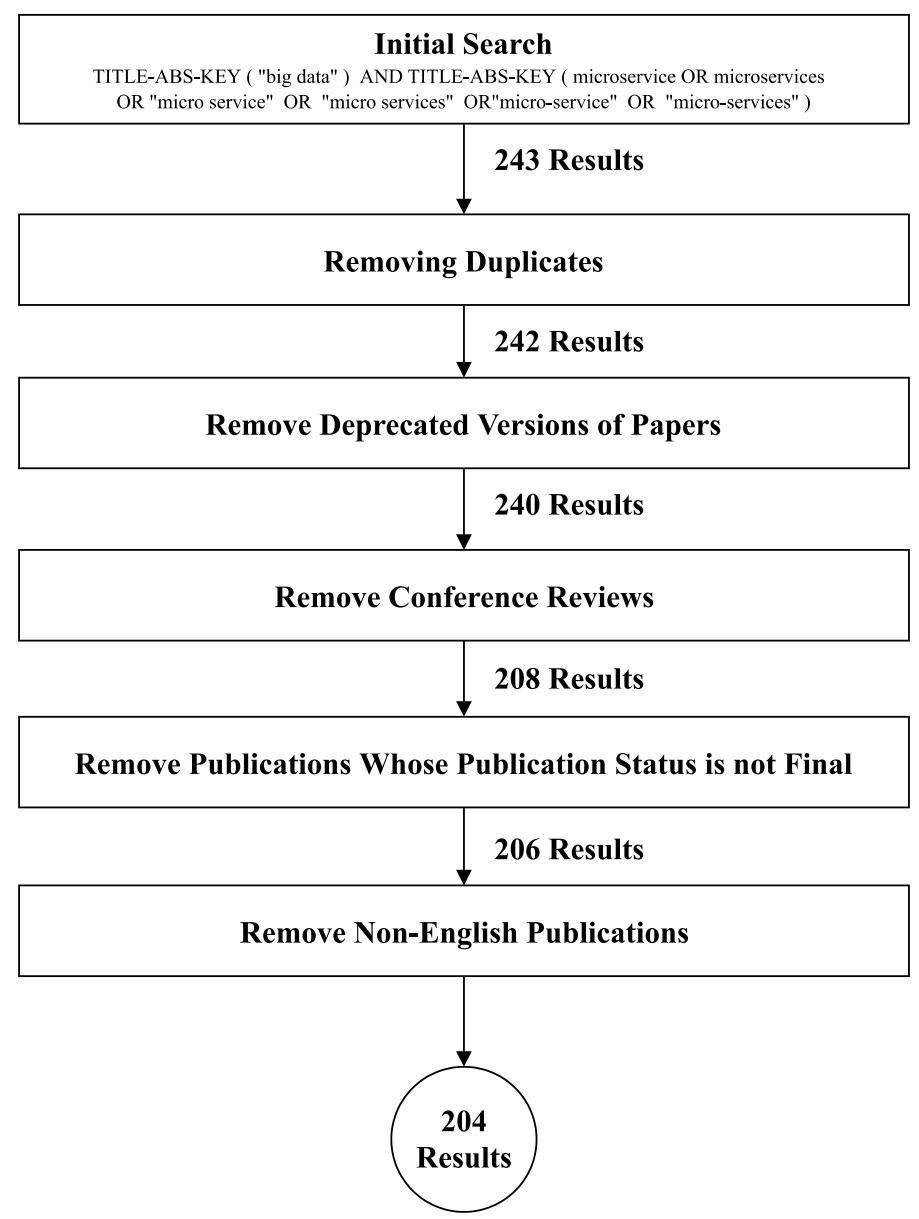

Figure 1. The filter process

The study's final criteria for inclusion and exclusion are outlined in Table 3. 
Table 3. Inclusion and exclusion criteria

\begin{tabular}{|l|l|}
\hline Inclusion criteria & Exclusion criteria \\
\hline Contribution is listed in Scopus & Contribution is a duplicate \\
\hline Contribution is connected to big data & An updated version of the contribution has been found \\
\hline Contribution is connected to microservices & Contribution is a "Conference Review" \\
\hline & Contribution stage is not "final" \\
\hline & Contribution is not written in English \\
\hline
\end{tabular}

\section{Results and Discussion}

In the following, the posed research questions will be answered, providing an overview of the current situation regarding research that combines the domains of big data and microservices as well as outlining avenues for future research.

\subsection{The Current Situation}

In this section, the first research question "What is the current situation in the research combining big data and microservices?" is being answered. For this purpose, the factors denominated in Table 4 are considered by using the analytical capabilities provided by Scopus. When amalgamated, those factors give a comprehensive picture of the current situation.

Table 4. Considered factors for answering RQ1

\begin{tabular}{|l|l|}
\hline ID & Regarded factor \\
\hline Factor 1 & What are the publications that focus on the topic? \\
\hline Factor 2 & What is their temporal distribution? \\
\hline Factor 3 & Which subject areas are they originating from? \\
\hline Factor 4 & Where are the found papers published? \\
\hline Factor 5 & The researchers of which countries are the main contributors? \\
\hline Factor 6 & How are the publications distributed amongst authors? \\
\hline Factor 7 & Which are the most cited publications? \\
\hline
\end{tabular}

At first, constituting the foundation for the following considerations, giving an overview of the available research and, therefore, taking Factor 1 into account, the results of the conducted search [14]-[16], [36], [49]-[245] are presented. Furthermore, the findings are discussed with the purpose of extracting valuable information and providing context where it is deemed necessary.

As shown in Table 5, which corresponds to Factor 2, the first papers fitting the search have not appeared before 2015 [36], [49]-[53]. However, when dropping the search term big data and just looking for the different variants of the term microservice, the earliest papers that are found were published in 2003 [246], [247]. The term big data can be traced back even further [5]. This shows that it has taken more than a decade until the combination of both domains has been scientifically explored. In conjunction with the oldest publication being less than six years old, this indicates that the corresponding research is still rather in its infancy.

While in the beginning there has been a constant increase in published papers, this does not hold true for the years 2020 and 2021. For the latter this can be easily explained with the search date being in June 2021 and several contributions probably not yet being registered. The former could be caused by the Covid-19 pandemic, which might have thwarted the corresponding research endeavors. And, while there is no explicit evidence for or against this hypothesis and Scopus overall lists more papers published in 2020 than in 2019, this is reversed when excluding the medical domain, which experienced a surge in publications, probably also caused by the pandemic. However, the number of papers found in the search for the year 2020 was still about 
34.1 percent higher than its equivalent for the years 2015, 2016 and 2017, as the first three years with findings, combined.

The deviation between the sum of the single values and the displayed total is caused by the limitation to two digits for this presentation, while the actual calculations use a higher precision. This phenomenon also applies to some of the following tables, but will not be explicitly mentioned any further.

Table 5. Distribution of publications by year

\begin{tabular}{|c|r|r|}
\hline Year & Publications & Percentage \\
\hline 2021 & 15 & $7.35 \%$ \\
\hline 2020 & 55 & $26.96 \%$ \\
\hline 2019 & 56 & $27.45 \%$ \\
\hline 2018 & 37 & $18.14 \%$ \\
\hline 2017 & 23 & $11.27 \%$ \\
\hline 2016 & 12 & $5.88 \%$ \\
\hline 2015 & 6 & $2.94 \%$ \\
\hline Total & 204 & $100.00 \%$ \\
\hline
\end{tabular}

Table 6 shows the distribution of publications by subject area, which corresponds to Factor 3 . This table is heavily dominated by "Computer Science" papers with 179 entries (87.75\%), followed by a group of contributions from "Engineering" with 62 papers (30.39\%), "Decision Sciences" with 51 papers $(25.00 \%)$, and "Mathematics" with 45 papers $(22.06 \%)$. While other domains also have a number of articles, their numbers are considerably lower. However, it is possible for one paper to belong to more than one category at the same time. As a result, in total, there are 427 attributions of subject areas to the 204 papers, implying that on average each paper is associated with slightly over two subject areas, which is reflected in the displayed percentage.

Table 6. Distribution of publications by subject area

\begin{tabular}{|l|r|r|}
\hline Subject area & Number & Percentage \\
\hline Computer Science & 179 & $87.75 \%$ \\
\hline Engineering & 62 & $30.39 \%$ \\
\hline Decision Sciences & 51 & $25.00 \%$ \\
\hline Mathematics & 45 & $22.06 \%$ \\
\hline Physics and Astronomy & 17 & $8.33 \%$ \\
\hline Social Sciences & 14 & $6.86 \%$ \\
\hline Business, Management and Accounting & 11 & $5.39 \%$ \\
\hline Energy & 11 & $5.39 \%$ \\
\hline Materials Science & 11 & $5.39 \%$ \\
\hline Medicine & 9 & $4.41 \%$ \\
\hline Environmental Science & 5 & $2.45 \%$ \\
\hline Earth and Planetary Sciences & 4 & $1.96 \%$ \\
\hline Neuroscience & 2 & $0.98 \%$ \\
\hline Agricultural and Biological Sciences & 1 & $0.49 \%$ \\
\hline Biochemistry, Genetics and Molecular Biology & 1 & $0.49 \%$ \\
\hline Chemical Engineering & 1 & $0.49 \%$ \\
\hline Chemistry & 1 & $0.49 \%$ \\
\hline Health Professions & 1 & $0.49 \%$ \\
\hline Psychology & 1 & $0.49 \%$ \\
\hline Total & 427 & $209.31 \%$ \\
\hline
\end{tabular}

While there are numerous available subject areas recorded in Scopus [248] and comparing the ones listed in Table 6 with the entire collection to highlight those that have not been associated with big data and microservices is not a promising approach, a more focused examination can potentially point out promising directions for future endeavors. Therefore, the occurrence of subject areas when searching for "big data", respectively the different spellings of "microservices" (as already outlined in the explanation of the search string) without any 
additional constraints is depicted in Figure 2. The subjects that are inside the dark gray circle in the center are taken from Table 6. They each have at least one associated publication that is concerned with both, big data and microservices. In the light gray sections, on the left (big data) and right (microservices) sides of the figure, the areas that only occurred when searching for the respective term but not the other one are assigned to it. However, those subject areas that appeared in both separate searches but not in this paper's primary search for papers that combine both topics are in the middle gray part in between the previously described sections of the depiction. Specifically these are dentistry, immunology and microbiology, pharmacology, toxicology and pharmaceutics, economics, econometrics and finance and arts and humanities. With them being compatible to both concepts but not being dealt with accordingly by now, they could be potentially auspicious fields for researchers to conduct pioneer work while still providing a strong certainty regarding the feasibility. Nevertheless, the same also applies to many of the subject areas that are mentioned in Table 6, since they are only present because of few papers or even just a single contribution, leaving a lot of room for novel studies and approaches.

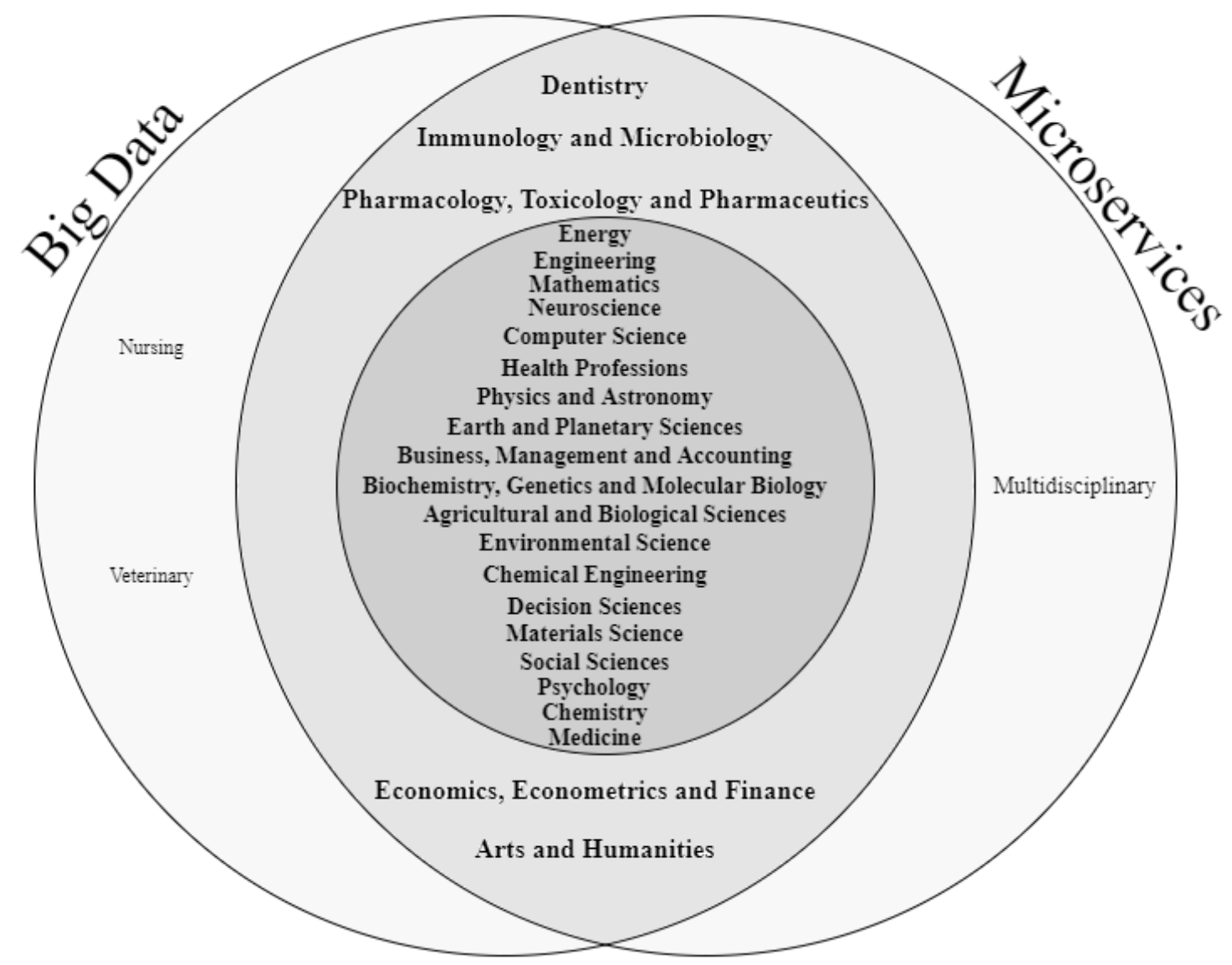

Figure 2. Depiction of the involved subject areas

As depicted in Table 7, the distribution of publications by their type after the filter process was applied is still heavily dominated by "Conference Paper" with 169 findings (82.84\%), followed by "Article" with 30 papers (14.71\%), 4 entries for "Book Chapter" (1.96\%) and 1 "Review" $(0.49 \%)$. The comparatively low number of journal articles, not even having one fifth of the volume of conference papers, could be considered another indicator of the corresponding research stream still being in a relatively early stage of its development. 
Table 7. Distribution of considered publications by type

\begin{tabular}{|l|r|r|}
\hline Type & Number & Percentage \\
\hline Conference Paper & 169 & $82.84 \%$ \\
\hline Article & 30 & $14.71 \%$ \\
\hline Book Chapter & 4 & $1.96 \%$ \\
\hline Review & 1 & $0.49 \%$ \\
\hline Total & 204 & $100.00 \%$ \\
\hline
\end{tabular}

Overall, the relevant papers originate from 142 sources, with each source containing an average of around 1.44 publications. While the "top lists" were generally intended to show the top 10, in case of additional entries with the same number of publications, those were also included. As a consequence, Table 8 comprises 11 sources, which together hold 62 papers. However, even with that extension, the top 3, consisting of ACM International Conference Proceeding Series, Journal Of Physics Conference Series, and Lecture Notes in Computer Science Including Subseries Lecture Notes in Artificial Intelligence And Lecture Notes In Bioinformatics, comprise almost half the papers of the top 11 and $14.70 \%$ of the entire literature corpus. Subsequently, Factor 4 is taken into account by regarding Table 7 and Table 8 in conjunction.

Table 8. Top 11 sources with the most publications

\begin{tabular}{|l|r|}
\hline Source & Number \\
\hline ACM International Conference Proceeding Series & 14 \\
\hline Journal Of Physics Conference Series & 8 \\
\hline $\begin{array}{l}\text { Lecture Notes in Computer Science Including Subseries Lecture Notes in Artificial Intelligence } \\
\text { And Lecture Notes In Bioinformatics }\end{array}$ & 8 \\
\hline Communications in Computer And Information Science & 6 \\
\hline IEEE Access & 6 \\
\hline Proceedings 2018 IEEE International Conference On Big Data Big Data 2018 & 4 \\
\hline Proceedings 2020 IEEE International Conference On Big Data Big Data 2020 & 4 \\
\hline $\begin{array}{l}\text { 2019 IEEE 4th International Conference On Cloud Computing And Big Data Analytics Icccbda } \\
\text { 2019 }\end{array}$ & 3 \\
\hline Advances In Intelligent Systems And Computing & 3 \\
\hline Proceedings 2019 IEEE International Conference On Big Data Big Data 2019 & 3 \\
\hline $\begin{array}{l}\text { IEEE 18th International Conference On Dependable Autonomic And Secure Computing } \\
\text { IEEE 18th International Conference On Pervasive Intelligence And Computing }\end{array}$ & 3 \\
IEEE 6th International Conference On Cloud And Big Data Computing and \\
IEEE 5th Cyber Science And Technology Congress Dasc Picom Cbdcom Cyberscitech 2020
\end{tabular}

When looking at the distribution of publications by country in Table 9, which provides the information related to Factor 5, it shows that a large proportion of papers comes from a small number of countries. However, for 1 of the 204 publications $(0.40 \%)$, a journal article, the country was stated as unknown. Just regarding the other entries, in total, there were 248 mentions of countries for the remaining 203 publications. The percentages for all the actual countries are also based on this number. It is noteworthy that the combined percentages add up to a value of above $100 \%$. This means that for all the contributions with known origins, on average, researchers of around 1.22 countries have collaborated.

In total, 756 authors were associated with the relevant publications. The number already incorporates the fact that Clemens Düpmeier was present with three separate entries, due to spelling (Clemens Düpmeier, Clemens Dupmeier and Clemens Duepmeier). Therefore, on average, each contribution has around 4.18 authors and each author has 1.13 papers. Of the 756 authors, $689(91.02 \%)$ had only a single article. The complete distribution of how many authors have which number of publications is shown in Table 10. It again points to the infancy of the research direction, since there is only a low number of heavily invested researchers, while most of the authors only contributed to a maximum of two publications. 
Table 9. Distribution of publications by country

\begin{tabular}{|l|r|r|l|r|r|}
\hline Country & Papers & Percentage & Country & Papers & Percentage \\
\hline China & 56 & $22.58 \%$ & South Africa & 2 & $0.81 \%$ \\
\hline United States & 35 & $14.11 \%$ & Taiwan & 2 & $0.81 \%$ \\
\hline Germany & 29 & $11.69 \%$ & Austria & 1 & $0.40 \%$ \\
\hline Italy & 14 & $5.65 \%$ & Belgium & 1 & $0.40 \%$ \\
\hline Canada & 13 & $5.24 \%$ & Denmark & 1 & $0.40 \%$ \\
\hline United Kingdom & 10 & $4.03 \%$ & Dominican Republic & 1 & $0.40 \%$ \\
\hline India & 9 & $3.63 \%$ & Egypt & 1 & $0.40 \%$ \\
\hline Brazil & 6 & $2.42 \%$ & Hungary & 1 & $0.40 \%$ \\
\hline France & 5 & $2.02 \%$ & Ireland & 1 & $0.40 \%$ \\
\hline Greece & 5 & $2.02 \%$ & Israel & 1 & $0.40 \%$ \\
\hline Australia & 4 & $1.61 \%$ & Latvia & 1 & $0.40 \%$ \\
\hline Morocco & 4 & $1.61 \%$ & Lebanon & 1 & $0.40 \%$ \\
\hline Portugal & 4 & $1.61 \%$ & Luxembourg & 1 & $0.40 \%$ \\
\hline Spain & 4 & $1.61 \%$ & Malaysia & 1 & $0.40 \%$ \\
\hline Switzerland & 4 & $1.61 \%$ & New Zealand & 1 & $0.40 \%$ \\
\hline Finland & 3 & $1.21 \%$ & Pakistan & 1 & $0.40 \%$ \\
\hline Japan & 3 & $1.21 \%$ & Panama & 1 & $0.40 \%$ \\
\hline Russian Federation & 3 & $1.21 \%$ & Romania & 1 & $0.40 \%$ \\
\hline Algeria & 2 & $0.81 \%$ & Serbia & 1 & $0.40 \%$ \\
\hline Bulgaria & 2 & $0.81 \%$ & Singapore & 1 & $0.40 \%$ \\
\hline Chile & 2 & $0.81 \%$ & Sweden & 1 & $0.40 \%$ \\
\hline Indonesia & 2 & $0.81 \%$ & Turkey & 1 & $0.40 \%$ \\
\hline Netherlands & 2 & $0.81 \%$ & Vietnam & 1 & $0.40 \%$ \\
\hline Slovenia & 2 & $0.81 \%$ & Undefined & 1 & $0.40 \%$ \\
\hline Total without undefined & & & 248 & $122.17 \%$ \\
\hline & & & & &
\end{tabular}

Table 10. Distribution of publications per author

\begin{tabular}{|c|r|r|}
\hline Number of publications & Authors & Percentage \\
\hline 8 & 1 & $0.13 \%$ \\
\hline 7 & 1 & $0.13 \%$ \\
\hline 6 & 0 & $0.00 \%$ \\
\hline 5 & 3 & $0.40 \%$ \\
\hline 4 & 3 & $0.40 \%$ \\
\hline 3 & 8 & $1.06 \%$ \\
\hline 2 & 51 & $6.74 \%$ \\
\hline 1 & 689 & $91.02 \%$ \\
\hline Total & 756 & $100.00 \%$ \\
\hline
\end{tabular}

The multiple occurrences of Clemens Düpmeier were also considered and corrected for when compiling the list of the most published authors depicted in Table 11. As for the list of the sources with the most publications, the initially intended top 10 was extended due to a parity in numbers and therefore comprises 16 authors. In case of parity on contributions, they are ordered alphabetically.

The list is led by Clemens Düpmeier and Veit Hagenmeyer having, respectively, 7 and 6 publications, with those 6 ones all being authored together. They are followed by Kurt Sandkuhl, Rainer Schmidt and Alfred Zimmermann, with 5 papers that were also each authored in cooperation of all three. Next in the list is Hamzeh Kazaei with 4 publications. The final cluster in this list, with 3 papers each, is formed by Hatem Khalloof and Shadi Shahoud whose 3 contributions were all created in cooperation with Düpmeier and Hagenmeyer as well as Hadi Bannazadeh, Eric Braun, Yu Ding, Antonino Galletta, Dierk Jugel, Alberto Leon-García, Kunying Li and Massimo Villari. With respect to the publication numbers, it is noteworthy that all of the list's authors together are responsible for 22 publications, but when adding all of the 
individual values, the result is 62 . This means that all of the top authors' papers were on average co-authored by about 2.82 members of the top 16 list.

Table 11. List of top 16 most published authors

\begin{tabular}{|c|c|c|c|}
\hline Author & Country & Institution & Papers \\
\hline Düpmeier, C. & Germany & Karlsruhe Institute of Technology & 7 \\
\hline Hagenmeyer, V. & Germany & Karlsruhe Institute of Technology & 6 \\
\hline Sandkuhl, K. & Germany & Universität Rostock & 5 \\
\hline Schmidt, R. & Germany & Ludwig-Maximilians-Universität München & 5 \\
\hline Zimmermann, A. & Germany & Hochschule Reutlingen & 5 \\
\hline Khazaei, H. & Canada & York University/University of Toronto & 4 \\
\hline Bannazadeh, H. & Canada & University of Toronto & 3 \\
\hline Braun, E. & Germany & Karlsruhe Institute of Technology & 3 \\
\hline Ding, $Y$. & China & $\begin{array}{l}\text { Research Institute of Petroleum Exploration and } \\
\text { Development }\end{array}$ & 3 \\
\hline Galletta, A. & Italy & Università degli Studi di Messina & 3 \\
\hline Jugel, D. & Germany & Hochschule Reutlingen & 3 \\
\hline Khalloof, H. & Germany & Karlsruhe Institute of Technology & 3 \\
\hline Leon-García, A. & Canada & University of Toronto & 3 \\
\hline Li, K. & China & $\begin{array}{l}\text { Research Institute of Petroleum Exploration and } \\
\text { Development }\end{array}$ & 3 \\
\hline Shahoud, S. & Germany & Karlsruhe Institute of Technology & 3 \\
\hline Villari, M. & Italy & Università degli Studi di Messina & 3 \\
\hline All 16 together & & & 22 \\
\hline
\end{tabular}

In Table 12, the letters in the row and column headers are the shortest unambiguous abbreviations of the surnames from the authors in Table 11.

Table 12. Collaboration matrix

\begin{tabular}{|c|c|c|c|c|c|c|c|c|c|c|c|c|c|c|c|c|}
\hline & Dü & Ha & Khal & Sh & Br & Sa & Sc & Z & J & Khaz & Ba & Le & Di & Li & G & V \\
\hline Dü & & 6 & 3 & 3 & 3 & & & & & & & & & & & \\
\hline Ha & 6 & & 3 & 3 & 2 & & & & & & & & & & & \\
\hline Khal & 3 & 3 & & 3 & & & & & & & & & & & & \\
\hline Sh & 3 & 3 & 3 & & & & & & & & & & & & & \\
\hline Br & 3 & 2 & & & & & & & & & & & & & & \\
\hline Sa & & & & & & 5 & 5 & 3 & & & & & & & \\
\hline Sc & & & & & 5 & & 5 & 3 & & & & & & & \\
\hline Z & & & & & & 5 & 5 & & 3 & & & & & & & \\
\hline J & & & & & & 3 & 3 & 3 & & & & & & & & \\
\hline Khaz & & & & & & & & & & 3 & 3 & & & & \\
\hline Ba & & & & & & & & & & 3 & & 3 & & & & \\
\hline Le & & & & & & & & & 3 & 3 & & & & & \\
\hline Di & & & & & & & & & & & & & 3 & & \\
\hline Li & & & & & & & & & & & & & 3 & & & \\
\hline G & & & & & & & & & & & & & & & 3 \\
\hline V & & & & & & & & & & & & & & & 3 & \\
\hline
\end{tabular}

The digit in a given cell shows the number of found publications co-authored by the researchers in the respective headers. It can be seen that the collaborations are within stable groups, which are not connected with each other. Furthermore, except for the two groups with Kurt Sandkuhl and Hamze Khazaei, the clusters each only comprise associates of a single organization. There are also no indirect connections between the clusters by each having one publication with an author who is in the group of authors with 2 contributions.

The list of the most cited authors is shown in Table 13. Since the top 10 is constituted by the authors of only two papers, this list was intended to comprise 20 entries, resulting in a list of 21 authors to account for parity. It is noteworthy, that 13 of the 21 authors $(61.90 \%)$ claimed their rank with just a single contribution. 
Table 13. List of the top 21 most cited authors

\begin{tabular}{|c|c|c|c|c|c|}
\hline Name & Country & Institution & Papers & Cit. & Avg. \\
\hline Gao, L. & Australia & Deakin University & 1 & 148 & 148.0 \\
\hline Garg, S. & Australia & University of Tasmania & 1 & 148 & 148.0 \\
\hline Georgakopoulos, D. & Australia & Swinburne University of Technology & 1 & 148 & 148.0 \\
\hline Jayaraman, P.P. & Australia & Swinburne University of Technology & 1 & 148 & 148.0 \\
\hline Naha, R.K. & Australia & University of Tasmania & 1 & 148 & 148.0 \\
\hline Ranjan, R. & $\begin{array}{l}\text { United } \\
\text { Kingdom }\end{array}$ & Newcastle University & 1 & 148 & 148.0 \\
\hline Xiang, Y. & Australia & Deakin University & 1 & 148 & 148.0 \\
\hline Jahn, M. & Germany & $\begin{array}{lccc}\text { Fraunhofer Institute for } & \text { Applied } \\
\text { Information Technology FIT } & \\
\end{array}$ & 1 & 135 & 135.0 \\
\hline Krylovskiy, A. & Germany & $\begin{array}{lcc}\text { Fraunhofer Institute for } & \text { Applied } \\
\text { Information Technology FIT } & \end{array}$ & 1 & 135 & 135.0 \\
\hline Patti, E. & Italy & Politecnico di Torino & 1 & 135 & 135.0 \\
\hline Deters, R. & Canada & University of Saskatchewan & 2 & 79 & 39.5 \\
\hline Samaniego, M. & Canada & University of Saskatchewan & 2 & 79 & 39.5 \\
\hline Khazaei, H. & Canada & York University/University of Toronto & 4 & 64 & 16.0 \\
\hline $\mathrm{Li}, \mathrm{Y}$. & China & Sichuan University & 1 & 50 & 50.0 \\
\hline Memon, R.A. & Pakistan & Sukkur IBA University & 1 & 50 & 50.0 \\
\hline Sun, L. & China & Sichuan University & 1 & 50 & 50.0 \\
\hline Cheng, D. & United States & Cornell University & 2 & 45 & 22.5 \\
\hline Delimitrou, $C$. & United States & Cornell University & 2 & 45 & 22.5 \\
\hline Gan, Y & United States & Cornell University & 2 & 45 & 22.5 \\
\hline $\mathrm{He}, \mathrm{Y}$. & United States & Cornell University & 2 & 45 & 22.5 \\
\hline Pancholi, M. & United States & Cornell University & 2 & 45 & 22.5 \\
\hline
\end{tabular}

In the relevant selection, on average, every paper has been cited 5.03 times. However, when looking at the distribution of citations in Table 14, it becomes apparent, that only a small number of publications is responsible for the majority of the citations. While 83 of the 204 contributions $(40.69 \%)$ have not been cited at all, the top 9 papers in conjunction already generate 529 of the 1026 citations (51.56\%). When ignoring all uncited items, for the remaining publications, the number of average citations increases to 8.48 per paper, which is still heavily influenced by a comparatively small number of outliers. With regard to the papers that were discarded due to being deprecated, their citations have been added to those of the newer versions to avoid omitting them. Furthermore, regarding Table 10, Table 11, Table 12 and Table 13 in conjunction, Factor 6 is covered.

To take Factor 7 into account, the 10 most cited publications are depicted in Table 15. While the number of citations does not necessarily always translate to the significance of a publication, it usually at least somewhat correlates. Furthermore, this is an objective measurement, whereas other approaches, as, for instance, an evaluation based on the perception of this article's authors would always bear the risk of subjectivity and bias.

When combining the presented information concerning the seven factors, a comprehensive overview of the current situation is achieved, which in turn constitutes the answer to RQ1. However, even though understanding the past and present of a research domain is important, it is probably even more essential to provide successive researchers with guidance and, therefore, facilitate the development of the research stream as a whole. While some inferences can already be drawn from the previously presented information, the next section is explicitly dedicated to the investigation of potential avenues for future research and thus the answer to RQ2. 
Table 14. Distribution of citations

\begin{tabular}{|c|c|c|c|c|}
\hline $\begin{array}{l}\text { Number } \\
\text { of } \\
\text { citations }\end{array}$ & Papers & $\begin{array}{l}\text { Sum of } \\
\text { citations }\end{array}$ & $\begin{array}{l}\text { Sum of all citations } \\
\text { up to the } \\
\text { respective level }\end{array}$ & $\begin{array}{l}\text { Percentage of all } \\
\text { citations up to the } \\
\text { respective level }\end{array}$ \\
\hline 148 & 1 & 148 & 148 & $14.42 \%$ \\
\hline 135 & 1 & 135 & 283 & $27.58 \%$ \\
\hline 52 & 1 & 52 & 335 & $32.65 \%$ \\
\hline 50 & 1 & 50 & 385 & $37.52 \%$ \\
\hline 35 & 1 & 35 & 420 & $40.94 \%$ \\
\hline 32 & 1 & 32 & 452 & $44.05 \%$ \\
\hline 27 & 1 & 27 & 479 & $46.69 \%$ \\
\hline 26 & 1 & 26 & 505 & $49.22 \%$ \\
\hline 24 & 1 & 24 & 529 & $51.56 \%$ \\
\hline 21 & 1 & 21 & 550 & $53.61 \%$ \\
\hline 18 & 1 & 18 & 568 & $55.36 \%$ \\
\hline 15 & 3 & 45 & 613 & $59.75 \%$ \\
\hline 14 & 4 & 56 & 669 & $65.20 \%$ \\
\hline 13 & 1 & 13 & 682 & $66.47 \%$ \\
\hline 12 & 1 & 12 & 694 & $67.64 \%$ \\
\hline 11 & 1 & 11 & 705 & $68.71 \%$ \\
\hline 10 & 1 & 10 & 715 & $69.69 \%$ \\
\hline 9 & 3 & 27 & 742 & $72.32 \%$ \\
\hline 8 & 1 & 8 & 750 & $73.10 \%$ \\
\hline 7 & 9 & 63 & 813 & $79.24 \%$ \\
\hline 6 & 3 & 18 & 831 & $80.99 \%$ \\
\hline 5 & 9 & 45 & 876 & $85.38 \%$ \\
\hline 4 & 9 & 36 & 912 & $88.89 \%$ \\
\hline 3 & 17 & 51 & 963 & $93.86 \%$ \\
\hline 2 & 15 & 30 & 993 & $96.78 \%$ \\
\hline 1 & 33 & 33 & 1026 & $100.00 \%$ \\
\hline 0 & 83 & 0 & 1026 & $100.00 \%$ \\
\hline
\end{tabular}

Table 15. List of the top 10 most cited publications

\begin{tabular}{|l|l|l|r|r|}
\hline \multicolumn{1}{|c|}{ Title } & Countries & \multicolumn{1}{|c|}{ Source } & Year & Citations \\
\hline $\begin{array}{l}\text { Fog computing: Survey of Trends, Architectures, } \\
\text { Requirements, and Research Directions [114] }\end{array}$ & Australia & Article & 2018 & 148 \\
\hline $\begin{array}{l}\text { Designing a Smart City Internet of Things Platform with } \\
\text { Microservice Architecture [36] }\end{array}$ & $\begin{array}{l}\text { Germany } \\
\text { Italy }\end{array}$ & $\begin{array}{l}\text { Conference } \\
\text { Paper }\end{array}$ & 2015 & 135 \\
\hline $\begin{array}{l}\text { Hosting Virtual IoT Resources on Edge-Hosts with } \\
\text { Blockchain [73] }\end{array}$ & Canada & $\begin{array}{l}\text { Conference } \\
\text { Paper }\end{array}$ & 2017 & 52 \\
\hline $\begin{array}{l}\text { An Open IoT Framework Based on Microservices } \\
\text { Architecture [72] }\end{array}$ & China & Article & 2017 & 50 \\
\hline $\begin{array}{l}\text { Seer: Leveraging Big Data to Navigate the Complexity } \\
\text { of Performance Debugging in Cloud Microservices [156] }\end{array}$ & $\begin{array}{l}\text { United } \\
\text { States }\end{array}$ & $\begin{array}{l}\text { Conference } \\
\text { Paper }\end{array}$ & 2019 & 35 \\
\hline $\begin{array}{l}\text { A Microservice-based Middleware for the Digital } \\
\text { Factory [69] }\end{array}$ & $\begin{array}{l}\text { Switzerland } \\
\text { Italy }\end{array}$ & Article & 2016 & 32 \\
\hline $\begin{array}{l}\text { Using Blockchain to Push Software-Defined IoT } \\
\text { Components onto Edge Hosts [64] }\end{array}$ & Canada & $\begin{array}{l}\text { Conference } \\
\text { Paper }\end{array}$ & 2017 & 27 \\
\hline $\begin{array}{l}\text { Introducing the New Paradigm of Social Dispersed } \\
\text { Computing: Applications, Technologies and Challenges } \\
\text { [118] }\end{array}$ & Spain & Review & 2018 & 22 \\
\hline $\begin{array}{l}\text { Delivering Elastic Containerized Cloud Applications to } \\
\text { Enable DevOps [82] }\end{array}$ & Canada & $\begin{array}{l}\text { Conference } \\
\text { Paper }\end{array}$ & 2017 & 21 \\
\hline $\begin{array}{l}\text { Design and Evaluation of a Scalable Smart City Software } \\
\text { Platform with Large-scale Simulations [155] }\end{array}$ & Brazil & Article & 2019 & 17 \\
\hline
\end{tabular}




\subsection{Avenues for Future Research}

When attempting to answer the second research question "Which are potential research areas or directions to facilitate the use of microservices in the big data domain?", it is at first necessary to understand the essence of the existing research that sparked the interest of the scientific community. Subsequently, potential avenues for future research can be identified.

Therefore, to get an understanding of the most popular research directions inside the domain, in the following, each of the top 10 most cited publications, shown in Table 15, will be briefly presented.

"Fog Computing Survey of Trends, Architectures, Requirements, and Research Directions" [114] focusses on how to connect big data producers like IoT systems with cloud computing. Especially when the data has to be processed in real-time, cloud computing can be too slow for the desired use case. This latency-aware computation is proposed to be solved by calculating on devices near the user. This "Fog computing paradigm" uses devices like smartphones and switches in close proximity, to process the data needed by the user. These devices are often just using their full processing power on peak hours and are idle otherwise. This decentralised approach comes with the drawback of limited resources available on each one of these devices, and potential failure of some. Microservices can be used to mitigate those problems by providing lightweight software and immediate deployment. Fog computing can be used in a number of fields using real-time processing, like virtual reality, healthcare, and smart homes. However, further research is still needed.

"Designing a Smart City Internet of Things Platform with Microservice Architecture" [36] presents the early stages of the „Dimmer“ Smart City Project. It consists of a platform and applications to involve stakeholders in increasing the energy efficiency of a city. A microservice architecture is used to independently develop and run sensor technologies, models, services, and applications. An "IoT Data Gateway" allows convenient data requests, while the data itself is stored decentralized. The decentralized approach allows the use of different protocols for different use cases and decreases the coordination required to manage a large interdisciplinary team. This also allows easier implementation of applications for web, desktop, and mobile. The benefits of a microservice architecture are already visible to them in these early stages of development, but will come at the cost of an increased complexity of distributed systems.

"Hosting Virtual IoT Resources on Edge-Hosts with Blockchain" [73] examines methods for shifting the computational load of IoT systems to the cloud. In the suggested approach, physical devices communicate with virtual resources, which are RESTful microservices. The virtual resource manages the IoT device and does the computation. An advantage of this approach is the ability to host multiple virtual resources on the same host. Additionally, it is shown that the management of the data and microservices can be done via blockchains. This creates large amounts of data and dependencies which can be tackled by big data technologies.

"An Open IoT Framework Based on Microservices Architecture" [72] proposes a decomposition of an IoT system into microservices. Subsequently, these microservices are connected to form a platform which can be extended and integrated into other applications. The frameworks consists of a core service that coordinates the system and eight microservices. Additionally, their system uses plugins to support heterogeneous devices. A series of microservices is used for hierarchical pre-processing of sensor data. It is shown that the proposed framework improves scalability and maintainability of IoT systems.

"Seer Leveraging Big Data to Navigate the Complexity of Performance Debugging in Cloud Microservices" [156] presents Seer, a diagnosis tool for detecting Quality of Service (QoS) violations in microservice applications. It focuses on detecting QoS violations proactively, thus reducing recovery times or avoiding violations completely. This is achieved using deep learning techniques to learn which patterns in tracing data indicate future QoS violations. Subsequently, Seer uses hardware monitoring to identify the cause of violations and suggests actions necessary 
for avoiding them. In a controlled environment, Seers has been shown to detect QoS violations accurately and improve performance predictability.

"A Microservice-based Middleware for the Digital Factory" [69] presents the implementation of a distributed middleware developed within the European MAYA project and tailored to enable scalable interoperability between enterprise applications and cyber-physical systems, with a particular focus on simulation tools. Overall, this middleware is intended to enable a digital factory. This is the first solution to rely on both Microservices and Big Data, realizing true digital synchronization while ensuring the security and confidentiality of sensitive factory data.

"Using Blockchain to Push Software-Defined IoT Components onto Edge Hosts" [64] presents the idea and evaluation of using virtual resources in combination with a permissionbased blockchain for provisioning IoT services on edge hosts. A big data architecture could be a solution for the blockchain technology.

"Introducing the New Paradigm of Social Dispersed Computing Applications, Technologies and Challenges" [118] gives a broad overview of social computing methods. Social computing applications are software where the output of a user's query is influenced by other users. For instance, in route planning. These types of applications are often implemented using microservices and involve Big Data methods to evaluate, analyze, and manage the data.

"Delivering Elastic Containerized Cloud Applications to Enable DevOps" [82] presents a method to enable an autonomous management system for multi-tier, data-intensive containerized applications based on a performance model of such systems. This makes it possible to develop microservice-based software and to test and monitor it efficiently and accurately. To analyze this large amount of data, big data analytics are applied.

"Design and Evaluation of a Scalable Smart City Software Platform with Large-scale Simulations" [155] shows the realization of a smart city platform with microservices. The opensource platform "InterSCity" provides web-based services to manage IoT services, as well as store and process data. A microservice architecture is used to work with the heterogeneous IoT services, and facilitate the future development and expansion of the platform. A focus of the project was set on scalability, as an important aspect to create a platform that can handle big data from IoT devices and thousands of user requests. A large-scale emulation is used to simulate the behavior of a city, with big data technologies managing the incurring amount of data. This emulation showed that the platform is highly scalable while still maintaining low response times.

While there are numerous additional contributions that are relevant to the domain, those ten presented papers are the most cited ones, which can, therefore, also be considered as particularly important when it comes to determining the current focus of the research stream. This especially applies, since the first results found in the search conducted in this study are from 2015, which entails that this analysis is not distorted by any extremely old and outdated publications.

To answer the question, which promising research topics could be of concern in combining the two domains (RQ2), the aforementioned relevant papers were thoroughly read and analyzed. Subsequently, it was concluded that two overarching directions were predominant and therefore mainly taken into consideration. On the one hand, the technical intersections between the papers were explored, and, on the other hand, the direction in which future research seems to move was contextually inferred.

Hereby, it stands out that none of the highlighted papers concentrate on the direct interplay between big data and microservices. Instead, they are focused on use cases where big data and microservices play an important but more technical role. Therefore, it is not examined, how the application of one exactly influences the application of the other with regards to the specific use cases. However, this could be an area of research to focus on in the future, as it seems that not much work has been done here so far.

In general, the focus of the current relevant research is rather on specific use cases. Although, it is also explored how big data can be used to facilitate the development of microservices; yet, the papers presented do not get specific about how they use the technology. Subsequently, future research could investigate, which aspects and technologies of big data make sense in this 
context, where the limits are, and what considerations have to be made. When looking at the inverse perspective, it is noticeable that, despite some exceptions [15], [249], there seems to be a gap regarding research on how microservices can be used for the development of big data applications.

Referring to the focus on specific use cases, it is apparent that the most cited papers of the domain have a very strong connection to IoT [36], [64], [72], [73], [114], [118]. They describe, how microservices can be used to implement large systems such as smart cities or smart factories on a large scale. These examples each involve large amounts of data that can be evaluated and used with the help of big data technologies. Yet, in most cases, there is no concrete description of how exactly those could be of use. Furthermore, as IoT is a vast domain, most examined topics have very few contentual overlaps, which makes the derivation of a coherent direction for future research difficult.

However, one topic in the IoT domain, which is standing out, is the exploration of the boundaries of fog computing [64], [73], [114] with regards to the application of different technologies. In fog computing, edge devices are used locally to carry out computations and store data in a distributed system. This applies very well to the IoT topic, where masses of raw data are collected via sensor input - often in distributed locations. The question of where and how to store and process this huge amount of data so that efficiency for the specific application is maximized, is crucial in this context and applies to smart factories and smart cities as well [36], [69].

An additional research domain, where microservices and big data can intersect, are social computing applications [118]. In this context, efficient frameworks need to be developed to deal with highly distributed systems and great amounts of data. Usually these systems are highly complex in their nature and expensive to compute, as input data influences the existing data.

Another interesting approach is detailed in [156], where deep learning, as a way of dealing with big data, is used to detect QoS violations in microservice based architectures. This could, for instance, be extended to using big data approaches for performance and security monitoring of microservice based architectures.

Furthermore, researchers could focus on an even more application-bound investigation of microservices and big data by analyzing domains, where microservices and big data are heavily used. However, to strengthen the research stream, it might be also beneficial if more researchers focused on creating reviews of this research area and its subareas, allowing others faster access relevant information and providing a general structure instead of a plethora of independent standalone projects.

\section{Conclusion and Directions for Future Research}

Since the use of microservices in combination with big data is rather new, this research direction is still in its infancy. Nevertheless, since 2015, a considerable amount of publications dealing with the topic have been created. However, to our knowledge, there has been no overview of those contributions. This article aims to make a contribution in this direction by pointing to those works that can make a valuable contribution to a research stream by constituting the groundwork for future research endeavors, which can build upon them [48]. For this purpose, a bibliometric study was conducted, comprising those papers that have a relation to big data as well as microservices. During the process it was identified, which publications exist (Factor 1) and how they are distributed across years (Factor 2), subject areas (Factor 3) and publication outlets (Factor 4). Furthermore, the authors of those contributions were regarded (Factor 5 and Factor 6) and the most cited publications were presented (Factor 7). In conjunction, those factors also provide the answer to RQ1 by outlining the current situation of the research stream.

Based on the findings of those analyses, there are several insights regarding future works in the area that can be derived. This in turn corresponds to RQ2. Firstly, amongst the most active authors, there are several clusters that have no connection to each other. If those groups of 
authors also shared ideas and cooperated with each other, this potentially holds synergies which might propel the research domain as a whole. Furthermore, there are two important research aspects, on the one hand, the use of big data to enhance microservices and, on the other hand, the utilization of microservices to realize big data applications. While both have their merits, especially the latter one could gain higher importance, since its allows to fulfil the rising need for flexibility in analytics solutions [13]. However, in either case, the development of the research should slowly move to more mature endeavors, resulting in a shift from the momentarily extremely predominant conference publications to more journal contributions. This way, over time, the accompanying increase in quality and the appearance in more prestigious outlets might spark the interest of other researchers, which might enrich the community long-term. Besides those aspects it can be expected that the factor time will also play a huge role in the growth of the research stream, since there was a significant and steady increase in the yearly number of publications, which was (likely) only stopped by the Covid-19 pandemic.

Another finding with regards to the content and the development of future research directions is that the heterogeneity of the domain leads to a high number of standalone projects. And while those each deal with potentially highly relevant issues, there is no overall research agenda. However, such an agenda might be beneficial. Yet, the intricacy of the topics of big data and microservices, especially when combined, makes it at least very hard to develop one that does justice to the underlying complexity. In general, big data and microservices, in this context, are "only" tools to create and improve products of different domains. Therefore, for future research, mainly focusing on application domains might be a promising approach. Yet, also future review papers that examine the relation of big data and microservices will be needed to provide prospective researchers with an easily accessible overview of the domain, lowering the barrier to entry and allowing to build upon existing knowledge [48].

Even though the present study is slightly limited by the fact that only a single database was used, since it is the presumably largest and most comprehensive one, the general findings can still be assumed to be valid. In the future, to further extend the insights in the domain, it could be beneficial to go beyond the scope of this bibliometric study and to conduct a comprehensive structured literature review [43], [44], [48] that sheds light on the state of the art and goes more in-depth regarding the respective contents of the relevant publications. While an overview of the most cited papers has already been given in the course of this work, performing such an analysis in a comprehensive manner is not the main focus of a bibliometric study, nevertheless, conducting such a review can be seen as a next step for facilitating the research concerning the interplay between big data and microservices. As aforementioned, this might help in gaining and forming new insights, best practices, guidelines, patterns and antipatterns, but also in highlighting especially relevant research gaps, which might attract further contributors that will help to advance not only the research, but also the practical application and combination of those two highly relevant and innovative tools.

\section{References}

[1] C. Dobre and F. Xhafa, "Intelligent services for Big Data science," Future Generation Computer Systems, vol. 37, pp. 267-281, 2014. Available: https://doi.org/10.1016/j.future.2013.07.014

[2] S. Yin and O. Kaynak, "Big Data for Modern Industry: Challenges and Trends [Point of View]," Proc. IEEE, vol. 103, no. 2, pp. 143-146, 2015. Available: https://doi.org/10.1109/JPROC.2015.2388958

[3] X. Jin, B. W. Wah, X. Cheng, and Y. Wang, "Significance and Challenges of Big Data Research," Big Data Research, vol. 2, no. 2, pp. 59-64, 2015. Available: https://doi.org/10.1016/j.bdr.2015.01.006

[4] T. Kolajo, O. Daramola, and A. Adebiyi, "Big data stream analysis: a systematic literature review," J Big Data, vol. 6, 2019. Available: https://doi.org/10.1186/s40537-019-0210-7

[5] F. X. Diebold, "On the Origin(s) and Development of the Term 'Big Data'," SSRN Journal, 2012. Available: https://doi.org/10.2139/ssrn.2152421 
[6] A. Gandomi and M. Haider, "Beyond the hype: Big data concepts, methods, and analytics," International Journal of Information Management, vol. 35, no. 2, pp. 137-144, 2015. Available: https://doi.org/10.1016/j.ijinfomgt.2014.10.007

[7] O. Müller, M. Fay, and J. Vom Brocke, "The Effect of Big Data and Analytics on Firm Performance: An Econometric Analysis Considering Industry Characteristics," Journal of Management Information Systems, vol. 35, no. 2, pp. 488-509, 2018. Available: https://doi.org/10.1080/07421222.2018.1451955

[8] T. Becker, "Big Data Usage," In New Horizons for a Data-Driven Economy, J. M. Cavanillas, E. Curry, and W. Wahlster, Eds., Cham: Springer International Publishing, pp. 143-165, 2016. Available: https://doi.org/10.1007/978-3-319-21569-3_8

[9] S. Fosso Wamba, A. Gunasekaran, S. Akter, S. J. Ren, R. Dubey, and S. J. Childe, "Big Data Analytics and Firm Performance: Effects of Dynamic Capabilities,” Journal of Business Research, vol. 70, pp. 356-365, 2017. Available: https://doi.org/10.1016/j.jbusres.2016.08.009

[10] J. Vom Brocke, C. Sonnenberg, and A. Simons, "Value-oriented Information Systems Design: The Concept of Potentials Modeling and its Application to Service-oriented Architectures," Bus. Inf. Syst. Eng., vol. 1, no. 3, pp. 223-233, 2009. Available: https://doi.org/10.1007/s12599-009-0046-3

[11] M. Volk, D. Staegemann, M. Pohl, and K. Turowski, "Challenging Big Data Engineering: Positioning of Current and Future Development," Proceedings of the 4th International Conference on Internet of Things, Big Data and Security, Heraklion, Crete, Greece, pp. 351-358, 2019. Available: https://doi.org/10.5220/0007748803510358

[12] M. Volk, D. Staegemann, S. Bosse, R. Häusler, and K. Turowski, "Approaching the (Big) Data Science Engineering Process," Proceedings of the 5th International Conference on Internet of Things, Big Data and Security, Prague, Czech Republic, pp. 428-435, 2020. Available: https://doi.org/10.5220/0009569804280435

[13] D. Staegemann, M. Volk, C. Daase, and K. Turowski, "Discussing Relations Between Dynamic Business Environments and Big Data Analytics," CSIMQ, no. 23, pp. 58-82, 2020. Available: https://doi.org/10.7250/csimq.2020-23.05

[14] M. Vrbaski, M. Bolic, and S. Majumdar, "A Performance Driven Micro Services-Based Architecture/System for Analyzing Noisy IoT Data," Proceedings of the 2019 19th IEEE/ACM International Symposium on Cluster, Cloud and Grid Computing (CCGRID), Larnaca, Cyprus, 2019. Available: https://doi.org/10.1109/CCGRID.2019.00031

[15] A. Freymann, F. Maier, K. Schaefer, and T. Böhnel, "Tackling the Six Fundamental Challenges of Big Data in Research Projects by Utilizing a Scalable and Modular Architecture," Proceedings of the 5th International Conference on Internet of Things, Big Data and Security, Prague, Czech Republic, pp. 249-256, 2020. Available: https://doi.org/10.5220/0009388602490256

[16] K. Miao, J. Li, W. Hong, and M. Chen, "A Microservice-Based Big Data Analysis Platform for Online Educational Applications," Scientific Programming, vol. 2020, pp. 1-13, 2020. Available: https://doi.org/10.1155/2020/6929750

[17] M. Volk, D. Staegemann, and K. Turowski, "Big Data," Springer Reference Wirtschaft, Handbuch Digitale Wirtschaft, T. Kollmann, ed., Wiesbaden: Springer Fachmedien Wiesbaden, pp. 1-18, 2020. Available: https://doi.org/10.1007/978-3-658-17345-6_71-1

[18] Gartner, Hype Cycle for Emerging Technologies, 2012. Available: https://www.gartner.com/en/documents/2100915/hype-cycle-for-emerging-technologies-2012. Accessed on January 17, 2021.

[19] S. Bahri, N. Zoghlami, M. Abed, and J. M. R. S. Tavares, "BIG DATA for Healthcare: A Survey," IEEE Access, vol. 7, pp. 7397-7408, 2019. Available: https://doi.org/10.1109/ACCESS.2018.2889180

[20] W. Raghupathi and V. Raghupathi, "Big data analytics in healthcare: promise and potential," Health Information Science and Systems, vol. 2, p. 3, 2014. Available: https://doi.org/10.1186/2047-2501-2-3

[21] L. Zhu, F. R. Yu, Y. Wang, B. Ning, and T. Tang, "Big Data Analytics in Intelligent Transportation Systems: A Survey," IEEE Trans. Intell. Transport. Syst., vol. 20, no. 1, pp. 383-398, 2019. Available: https://doi.org/10.1109/TITS.2018.2815678

[22] J. Li, L. Xu, L. Tang, S. Wang, and L. Li, "Big data in tourism research: A literature review," Tourism Management, vol. 68, pp. 301-323, 2018. Available: https://doi.org/10.1016/j.tourman.2018.03.009

[23] A. Parlina, K. Ramli, and H. Murfi, "Theme Mapping and Bibliometrics Analysis of One Decade of Big Data Research in the Scopus Database," Information, vol. 11, no. 2, pp. 69-94, 2020. Available: https://doi.org/10.3390/info11020069

[24] W. L. Chang and N. Grady, NIST Big Data Interoperability Framework: Volume 1, Definitions. NIST, 2019. Available: https://doi.org/10.6028/NIST.SP.1500-1r2 
[25] N. Khan, M. Alsaqer, H. Shah, G. Badsha, A. A. Abbasi, and S. Salehian, "The 10 Vs, Issues and Challenges of Big Data," Proceedings of the 2018 International Conference on Big Data and Education, Honolulu HI USA, pp. 52-56, 2018. Available: https://doi.org/10.1145/3206157.3206166

[26] A. Gardiner, C. Aasheim, P. Rutner, and S. Williams, "Skill Requirements in Big Data: A Content Analysis of Job Advertisements," Journal of Computer Information Systems, vol. 58, no. 4, pp. 374-384, 2018. Available: https://doi.org/10.1080/08874417.2017.1289354

[27] P. Ataei and A. Litchfield, "Big Data Reference Architectures, a systematic literature review," Australasian Conference on Information Systems (ACIS) 2020, Wellington, New Zealand, 2020.

[28] M. Volk, D. Staegemann, S. Bosse, A. Nahhas, and K. Turowski, "Towards a Decision Support System for Big Data Projects,” WI2020 Zentrale Tracks, N. Gronau, M. Heine, K. Poustcchi, and H. Krasnova, eds.: GITO Verlag, pp. 357-368, 2020. Available: https://doi.org/10.30844/wi_2020_c10-behnen

[29] A. M. Fernández, D. Gutiérrez-Avilés, A. Troncoso, and F. Martínez-Álvarez, “Automated Deployment of a Spark Cluster with Machine Learning Algorithm Integration,” Big Data Research, vol. 19-20, p. 100135, 2020. Available: https://doi.org/10.1016/j.bdr.2020.100135

[30] P. Jamshidi, C. Pahl, N. C. Mendonca, J. Lewis, and S. Tilkov, "Microservices: The Journey So Far and Challenges Ahead," IEEE Softw., vol. 35, no. 3, pp. 24-35, 2018. Available: https://doi.org/10.1109/MS.2018.2141039

[31] I. Nadareishvili, R. Mitra, M. McLarty, and M. Amundsen, Microservice architecture: Aligning principles, practices, and culture. Beijing, Boston, Farnham, Sebastopol, Tokyo: O’Reilly, 2016.

[32] P. Drews, I. Schirmer, B. Horlach, and C. Tekaat, "Bimodal Enterprise Architecture Management: The Emergence of a New EAM Function for a BizDevOps-Based Fast IT," 2017 IEEE 21st International Enterprise Distributed Object Computing Workshop (EDOCW), Quebec City, QC, pp. 57-64, 2017. Available: https://doi.org/10.1109/EDOCW.2017.18

[33] J. Lewis and M. Fowler, Microservices. Available: https://martinfowler.com/articles/microservices.html. Accessed on January 20, 2021.

[34] M. E. Conway, "How do committees invent?," Design Organization Criteria, April 1968, pp. 28-31, 1968.

[35] D. Faitelson, R. Heinrich, and S. Tyszberowicz, "Functional Decomposition for Software Architecture Evolution," Communications in Computer and Information Science, Model-Driven Engineering and Software Development, L. F. Pires, S. Hammoudi, and B. Selic, eds., Cham: Springer International Publishing, pp. 377-400, 2018. Available: https://doi.org/10.1007/978-3-319-94764-8_16

[36] A. Krylovskiy, M. Jahn, and E. Patti, "Designing a Smart City Internet of Things Platform with Microservice Architecture," 2015 3rd International Conference on Future Internet of Things and Cloud (FiCloud 2015), Rome, Italy, pp. 25-30, 2015. Available: https://doi.org/10.1109/FiCloud.2015.55

[37] S. Fosso Wamba, M. N. C. Angéla, and E. E. J. Bosco, "Big Data, the Internet of Things, and Smart City Research: A Literature Review and Research Agenda," Lecture Notes in Electrical Engineering, EAI International Conference on Technology, Innovation, Entrepreneurship and Education, A. Reyes-Munoz, P. Zheng, D. Crawford, and V. Callaghan, eds., Cham: Springer International Publishing, pp. 263-276, 2019. Available: https://doi.org/10.1007/978-3-030-02242-6_20

[38] E. W. T. Ngai and F. K. T. Wat, "A literature review and classification of electronic commerce research," Information \& Management, vol. 39, no. 5, pp. 415-429, 2002. Available: https://doi.org/10.1016/S03787206(01)00107-0

[39] S. Fosso Wamba, A. Anand, and L. Carter, "A literature review of RFID-enabled healthcare applications and issues," International Journal of Information Management, vol. 33, no. 5, pp. 875-891, 2013. Available: https://doi.org/10.1016/j.ijinfomgt.2013.07.005

[40] G. Paré, M.-C. Trudel, M. Jaana, and S. Kitsiou, "Synthesizing information systems knowledge: A typology of literature reviews," Information \& Management, vol. 52, no. 2, pp. 183-199, 2015. Available: https://doi.org/10.1016/j.im.2014.08.008

[41] B. Kitchenham, P. Brereton, D. Budgen, M. Turner, J. Bailey, and S. Linkman, "Systematic literature reviews in software engineering - A systematic literature review," Information and Software Technology, vol. 51, no. 1, pp. 7-15, 2009. Available: https://doi.org/10.1016/j.infsof.2008.09.009

[42] M. Wißotzki, K. Sandkuhl, A. K. Dunkel, and L. V. Christina, "State of research in reuse of enterprise models: Systematic literature analysis of CAISE, EMMSAD, ICIS and INCOM," Proceedings of the IADIS International Conference Information Systems 2012, Berlin, Germany, 2012.

[43] J. Webster and R. T. Watson, "Analyzing the Past to Prepare for the Future: Writing a Literature Review," $M I S Q$, vol. 26, no. 2, pp. xiii-xxiii, 2002. 
[44] C. Okoli, "A Guide to Conducting a Standalone Systematic Literature Review," CAIS, vol. 37, pp. 879-910, 2015. Available: https://doi.org/10.17705/1CAIS.03743

[45] Elsevier, Scopus ${ }^{\circledR}$ Expertly curated abstract \& citation database. Available: https://www.elsevier.com/solutions/scopus. Accessed on January 4, 2021.

[46] H. Hu et al., "TopoLens: Building a CyberGIS community data service for enhancing the usability of highresolution national topographic datasets," Proceedings of the XSEDE16 Conference on Diversity, Big Data, and Science at Scale, Miami USA, pp. 1-8, 2016. Available: https://doi.org/10.1145/2949550.2949652

[47] S. Shahoud, S. Gunnarsdottir, H. Khalloof, C. Duepmeier, and V. Hagenmeyer, "Facilitating and Managing Machine Learning and Data Analysis Tasks in Big Data Environments using Web and Microservice Technologies," Proceedings of the 11th International Conference on Management of Digital EcoSystems, Limassol Cyprus, pp. 80-87, 2019. Available: https://doi.org/10.1145/3297662.3365807

[48] J. Vom Brocke, A. Simons, B. Niehaves, K. Reimer, R. Plattfaut, and A. Cleven, "Reconstructing the Giant: On the Importance of Rigour in Documenting the Literature Search Process," Proceedings of the ECIS 2009, Verona, Italy, 2009.

[49] H.-M. Chen, R. Kazman, S. Haziyev, V. Kropov, and D. Chtchourov, "Architectural Support for DevOps in a Neo-Metropolis BDaaS Platform," 2015 IEEE 34th Symposium on Reliable Distributed Systems Workshops, Montreal, QC, Canada, pp. 25-30, 2015. Available: https://doi.org/10.1109/SRDSW.2015.14

[50] C. Düpmeier, K.-U. Stucky, R. Mikut, and V. Hagenmeyer, "A Concept for the Control, Monitoring and Visualization Center in Energy Lab 2.0," Lecture Notes in Computer Science, Energy Informatics, S. Gottwalt, L. König, and H. Schmeck, eds., Cham: Springer International Publishing, pp. 83-94, 2015. Available: https://doi.org/10.1007/978-3-319-25876-8_8

[51] F. Andry, R. Ridolfo, and J. Huffman, "Migrating Healthcare Applications to the Cloud through Containerization and Service Brokering," Proceedings of the International Conference on Health Informatics, Lisbon, Portugal, pp. 164-171, 2015. Available: https://doi.org/10.5220/0005249601640171

[52] P. Nicolaescu and R. Klamma, "A Methodology and Tool Support for Widget-Based Web Application Development," Lecture Notes in Computer Science, Engineering the Web in the Big Data Era, P. Cimiano, F. Frasincar, G.-J. Houben, and D. Schwabe, eds., Cham: Springer International Publishing, pp. 515-532, 2015. Available: https://doi.org/10.1007/978-3-319-19890-3_33

[53] I. Koren, P. Nicolaescu, and R. Klamma, "Collaborative Drawing Annotations on Web Videos," Lecture Notes in Computer Science, Engineering the Web in the Big Data Era, P. Cimiano, F. Frasincar, G.-J. Houben, and D. Schwabe, eds., Cham: Springer International Publishing, pp. 671-674, 2015. Available: https://doi.org/10.1007/978-3-319-19890-3_54

[54] P. H. Carns et al., "Enabling NVM for data-Intensive scientific services," 4th Workshop on Interactions of NVM/Flash with Operating Systems and Workloads, Savannah, USA, 2016.

[55] M. Buchler, G. Franzini, E. Franzini, and T. Eckart, "Mining and analysing one billion requests to linguistic services," 2016 IEEE International Conference on Big Data (Big Data), Washington DC, USA, pp. 3230 3239, 2016. Available: https://doi.org/10.1109/BigData.2016.7840979

[56] T. Fukui, "A systems approach to big data technology applied to supply chain," 2016 IEEE International Conference on Big Data (Big Data), Washington DC, USA, pp. 3732-3736, 2016. Available: https://doi.org/10.1109/BigData.2016.7841041

[57] Y. Ardulov, S. Mescheryakov, and Shchemelinin, "Dynamic load balancing and continuous service delivery in a big cloud infrastructure," Proceedings of imPACt 2016 - Internet, Mobile, Performance and Capacity, Cloud and Technology 2016, San Diego, CA, USA, 2016.

[58] A. Gopu, S. Hayashi, M. D. Young, R. Kotulla, R. Henschel, and D. Harbeck, "Trident: scalable compute archives: workflows, visualization, and analysis," Software and Cyberinfrastructure for Astronomy IV, Edinburgh, United Kingdom, 2016. Available: https://doi.org/10.1117/12.2233111

[59] H.-M. Chen, R. Kazman, S. Haziyev, V. Kropov, and D. Chtchourov, "Big Data as a Service: A NeoMetropolis Model Approach for Innovation," 49th Hawaii International Conference on System Sciences (HICSS), Koloa, HI, USA, pp. 5458-5467, 2016. Available: https://doi.org/10.1109/HICSS.2016.674

[60] A. Iosup, S. Kounev, and K. Sachs, "SPEC Research Group's Cloud Working Group," Proceedings of the 7th ACM/SPEC on International Conference on Performance Engineering, Delft, Netherlands, pp. 127-128, 2016. Available: https://doi.org/10.1145/2851553.2858675

[61] W. Scarborough, C. Arnold, and M. Dahan, "Case Study: Microservice evolution and software lifecycle of the XSEDE user portal API," Proceedings of the XSEDE16 Conference on Diversity, Big Data, and Science at Scale, Miami USA, pp. 1-5, 2016. Available: https://doi.org/10.1145/2949550.2949655 
[62] S. Julian, M. Shuey, and S. Cook, "Containers in Research: Initial experiences with lightweight infrastructure," Proceedings of the XSEDE16 Conference on Diversity, Big Data, and Science at Scale, Miami USA, pp. 1-6, 2016. Available: https://doi.org/10.1145/2949550.2949562

[63] A. M. Hendawi, M. Khalefa, H. Liu, M. Ali, and J. A. Stankovic, "A vision for micro and macro location aware services," Proceedings of the 24th ACM SIGSPATIAL International Conference on Advances in Geographic Information Systems, Burlingame California, pp. 1-4, 2016. Available: https://doi.org/10.1145/2996913.2996977

[64] M. Samaniego and R. Deters, "Using Blockchain to push Software-Defined IoT Components onto Edge Hosts," Proceedings of the International Conference on Big Data and Advanced Wireless Technologies, Blagoevgrad, Bulgaria, pp. 1-9, 2016. Available: https://doi.org/10.1145/3010089.3016027

[65] R. Debab and W.-K. Hidouci, "Towards a more reliable and robust Cloud Meta-Operating System based on heterogeneous kernels," Proceedings of the International Conference on Big Data and Advanced Wireless Technologies, Blagoevgrad, Bulgaria, pp. 1-13, 2016. Available: https://doi.org/10.1145/3010089.3010092

[66] E. Braun, T. Schlachter, C. Düpmeier, K.-U. Stucky, and W. Suess, "A Generic Microservice Architecture for Environmental Data Management," IFIP Advances in Information and Communication Technology, Environmental Software Systems. Computer Science for Environmental Protection, J. Hřebíček, R. Denzer, G. Schimak, and T. Pitner, eds., Cham: Springer International Publishing, pp. 383-394, 2017. Available: https://doi.org/10.1007/978-3-319-89935-0_32

[67] I. Ermilov et al., "Managing Lifecycle of Big Data Applications," Communications in Computer and Information Science, Knowledge Engineering and Semantic Web, P. Różewski and C. Lange, eds., Cham: Springer International Publishing, pp. 263-276, 2017. Available: https://doi.org/10.1007/978-3-319-69548$8 \_18$

[68] N. J. Wani, S. P. Mohanty, S. Purini, and D. M. Sharma, “Anuvaad Pranaali: A RESTful API for Machine Translation," Lecture Notes in Computer Science, Service-Oriented Computing - ICSOC 2016 Workshops, K. Drira et al., eds., Cham: Springer International Publishing, pp. 179-183, 2017. Available: https://doi.org/10.1007/978-3-319-68136-8_20

[69] M. Ciavotta, M. Alge, S. Menato, D. Rovere, and P. Pedrazzoli, "A Microservice-based Middleware for the Digital Factory,” Procedia Manufacturing, vol. 11, pp. 931-938, 2017. Available: https://doi.org/10.1016/j.promfg.2017.07.197

[70] J. Kampars and K. Pinka, “Auto-Scaling and Adjustment Platform for Cloud-Based Systems,” ETR, vol. 2, p. 52, 2017. Available: https://doi.org/10.17770/etr2017vol2.2591

[71] Y. Verginadis, I. Alshabani, G. Mentzas, and N. Stojanovic, "PrEstoCloud: Proactive Cloud Resources Management at the Edge for Efficient Real-Time Big Data Processing," Proceedings of the 7th International Conference on Cloud Computing and Services Science, Porto, Portugal, 2017, pp. 611-617. Available: https://doi.org/10.5220/0006359106110617

[72] L. Sun, Y. Li, and R. A. Memon, “An open IoT framework based on microservices architecture," China Commun., vol. 14, no. 2, pp. 154-162, 2017. Available: https://doi.org/10.1109/CC.2017.7868163

[73] M. Samaniego and R. Deters, "Hosting Virtual IoT Resources on Edge-Hosts with Blockchain," Proceedings of the 2016 16th IEEE International Conference on Computer and Information Technology - CIT 2016 and the 2016 6th International Symposium on Cloud and Service Computing - IEEE SC2 2016, 2016 International Symposium on Security and Privacy in Social Networks and Big Data - SocialSec 2016, Nadi, Fiji, pp. 116-119, 2016. Available: https://doi.org/10.1109/CIT.2016.71

[74] E. Bionda et al., "A demonstrator tool to provide the network operator with microservices based on big data and semantic web technologies," REPQJ, vol. 1, no. 15, pp. 137-142, 2017. Available: https://doi.org/10.24084/repqj15.250

[75] F. Z. Benchara, M. Youssfi, O. Bouattane, and H. Ouajji, "A new efficient distributed computing middleware based on cloud micro-services for HPC," 5th International Conference on Multimedia Computing and Systems (ICMCS), Marrakech, Morocco, pp. 354-359, 2016. Available: https://doi.org/10.1109/ICMCS.2016.7905644

[76] F. Kelbert et al., "SecureCloud: Secure big data processing in untrusted clouds," Proceedings of the 2017 Design, Automation \& Test in Europe, Swisstech, Lausanne, Switzerland, pp. 282-285, 2017. Available: https://doi.org/10.23919/DATE.2017.7926999

[77] X. Gao and M. Uehara, "Design of a Sports Mental Cloud," 31st International Conference on Advanced Information Networking and Applications Workshops (WAINA), Taipei, Taiwan, pp. 443-448, 2017. Available: https://doi.org/10.1109/WAINA.2017.33 
[78] H. Lin et al., "Research on building an innovative electric power marketing business application system based on cloud computing and microservices architecture technologies," IEEE 2nd International Conference on Cloud Computing and Big Data Analysis (ICCCBDA), Chengdu, China, pp. 246-253, 2017. Available: https://doi.org/10.1109/ICCCBDA.2017.7951919

[79] X. Gao, M. Uehara, K. Aoki, and C. Kato, "Prototyping Sports Mental Cloud," 5th Intl Conf on Applied Computing and Information Technology/4th Intl Conf on Computational Science/Intelligence and Applied Informatics/2nd Intl Conf on Big Data, Cloud Computing, Data Science (ACIT-CSII-BCD), Hamamatsu, Japan, pp. 141-146, 2017. Available: https://doi.org/10.1109/ACIT-CSII-BCD.2017.25

[80] D. C. Spell et al., "Flux: Groupon's automated, scalable, extensible machine learning platform," IEEE International Conference on Big Data (Big Data), Boston, MA, pp. 1554-1559, 2017. Available: https://doi.org/10.1109/BigData.2017.8258089

[81] H. Alipour and Y. Liu, "Online machine learning for cloud resource provisioning of microservice backend systems," IEEE International Conference on Big Data (Big Data), Boston, MA, pp. 2433-2441, 2017. Available: https://doi.org/10.1109/BigData.2017.8258201

[82] C. Barna, H. Khazaei, M. Fokaefs, and M. Litoiu, "Delivering Elastic Containerized Cloud Applications to Enable DevOps," IEEE/ACM 12th International Symposium on Software Engineering for Adaptive and SelfManaging Systems - SEAMS 2017, Buenos Aires, Argentina, pp. 65-75, 2017. Available: https://doi.org/10.1109/SEAMS.2017.12

[83] S. Murphy, V. Castro, and K. Mandl, "Grappling with the Future Use of Big Data for Translational Medicine and Clinical Care," Yearbook of Medical Informatics, vol. 26, no. 1, pp. 96-102, 2017. https://doi.org/10.15265/IY-2017-020

[84] H. Khazaei, H. Bannazadeh, and A. Leon-Garcia, "End-to-end management of IoT applications," IEEE Conference on Network Softwarization (NetSoft), Bologna, Italy, pp. 1-3, 2017. Available: https://doi.org/10.1109/NETSOFT.2017.8004252

[85] T. Zheng, Y. Zhang, X. Zheng, M. Fu, and X. Liu, "BigVM: A Multi-Layer-Microservice-Based Platform for Deploying SaaS," 5th International Conference on Advanced Cloud and Big Data (CBD), Shanghai, China, pp. 45-50, 2017. Available: https://doi.org/10.1109/CBD.2017.16

[86] Y. Sastri, K. Feldhoff, J. Starruß, R. Jäkel, and R. Müller-Pfefferkorn, "A Workflow for the Integral Performance Analysis of Cloud Applications Using Monitoring and Tracing Techniques," Proceedings of the 2017 International Conference on Cloud and Big Data Computing - ICCBDC 2017, London, United Kingdom, pp. 73-78, 2017. https://doi.org/10.1145/3141128.3141132

[87] X. Wang, X. Sun, Z. Hao, and H. Li, "Research on the Construction of Resource Sharing Platform Based on MicroService," International Conference on Smart Grid and Electrical Automation (ICSGEA), Changsha, pp. 713-717, 2017. Available: https://doi.org/10.1109/ICSGEA.2017.25

[88] H. Khazaei, H. Bannazadeh, and A. Leon-Garcia, "SAVI-IoT: A Self-Managing Containerized IoT Platform," IEEE 5th International Conference on Future Internet of Things and Cloud, pp. 227-234, 2017. Available: https://doi.org/10.1109/FiCloud.2017.27

[89] A. Zimmermann, R. Schmidt, and K. Sandkuhl, "Enterprise composition architecture for micro-granular digital services and products," Proceedings of the 27th International Conference on Information Systems Development: Designing Digitalization, Lund, Sweden, 2018.

[90] Y. Gan, M. Pancholi, D. Cheng, S. Hu, Y. He, and C. Delimitrou, "Seer: Leveraging big data to navigate the complexity of cloud debugging," 10th USENIX Workshop on Hot Topics in Cloud Computing, Boston, USA, 2018.

[91] R. Kang, Z. Zhou, J. Liu, Z. Zhou, and S. Xu, "Distributed Monitoring System for Microservices-Based IoT Middleware System," Lecture Notes in Computer Science, Cloud Computing and Security, X. Sun, Z. Pan, and E. Bertino, eds., Cham: Springer International Publishing, pp. 467-477, 2018. Available: https://doi.org/10.1007/978-3-030-00006-6_43

[92] A. Pedroso, B. L. Lopes, J. Correia, F. Araujo, J. Cardoso, and R. P. Paiva, “A Data Mining Service for NonProgrammers," Proceedings of the 10th International Joint Conference on Knowledge Discovery, Knowledge Engineering and Knowledge Management, Seville, Spain, pp. 340-346, 2018. Available: https://doi.org/10.5220/0007226003400346

[93] W. Lin, F. Xu, M. Ma, and P. Wang, "RBD: A Reference Railway Big Data System Model," Lecture Notes in Computer Science, Smart Computing and Communication, M. Qiu, ed., Cham: Springer International Publishing, pp. 261-270, 2018. Available: https://doi.org/10.1007/978-3-030-05755-8_26

[94] M. Kleehaus, Ö. Uludağ, P. Schäfer, and F. Matthes, "MICROLYZE: A Framework for Recovering the Software Architecture in Microservice-Based Environments," Lecture Notes in Business Information 
Processing, Information Systems in the Big Data Era: CAiSE forum 2018, J. Mendling and H. Mouratidis, eds., Springer, pp. 148-162, 2018. Available: https://doi.org/10.1007/978-3-319-92901-9_14

[95] T. Engel, M. Langermeier, B. Bauer, and A. Hofmann, "Evaluation of Microservice Architectures: A Metric and Tool-Based Approach," Lecture Notes in Business Information Processing, Information SystemS in the Big Data Era: Caise forum 2018, J. Mendling and H. Mouratidis, eds., Springer, pp. 74-89, 2018. Available: https://doi.org/10.1007/978-3-319-92901-9_8

[96] M. D’Antonio, P. D’Onorio de Meo, C. Cacciari, and G. Fiameni, "Characterization of Genomic Data Using Graph Databases," Advances in Parallel Computing, vol. 32, pp. 423-432, 2018. Available: https://doi.org/10.3233/978-1-61499-843-3-423

[97] F. Gao, "Frameworks for Big Data Integration, Warehousing, and Analytics," Big Data Application in Power Systems, Elsevier, pp. 57-73, 2018. Available: https://doi.org/10.1016/B978-0-12-811968-6.00004-8

[98] Y. Lu, W. Liu, and H. Cui, "MSA vs. MVC: Future Trends for Big Data Processing Platforms," Lecture Notes in Computer Science, Smart Computing and Communication, M. Qiu, ed., Springer, pp. 310-320, 2018. Available: https://doi.org/10.1007/978-3-319-73830-7_31

[99] P. Raj, "The Hadoop Ecosystem Technologies and Tools," Advances in Computers, Elsevier, vol. 109, pp. 279-320, 2018. Available: https://doi.org/10.1016/bs.adcom.2017.09.002

[100] B. I. Ismail, R. Kandan, E. M. Goortani, M. N. M. Mydin, M. F. Khalid, and O. H. Hoe, "Reference architecture for search infrastructure," 7th IEEE International Conference on Control System, Computing and Engineering (ICCSCE), Penang, p. 115-120, 2017. Available: https://doi.org/10.1109/ICCSCE.2017.8284390

[101] J. Yin, R. Ali, L. Li, W. Ma, and A. Ali, "Edge network model based on double dimension," IEEE 8th Annual Computing and Communication Workshop and Conference (CCWC), Las Vegas, NV, pp. 341-346, 2018. Available: https://doi.org/10.1109/CCWC.2018.8301694

[102] P. Lipton, D. Palma, M. Rutkowski, and D. A. Tamburri, "TOSCA Solves Big Problems in the Cloud and Beyond!" IEEE Cloud Comput., vol. 5, no. 2, pp. 37-47, 2018. Available: https://doi.org/10.1109/MCC.2018.022171666

[103] H. Zeng, B. Wang, W. Deng, and J. Tang, “A Prototype for Analyzing the Internet Routing System Based on Spark and Docker," IEEE 7th International Symposium on Cloud and Service Computing (SC2), Kanazawa, pp. 267-270, 2017. Available: https://doi.org/10.1109/SC2.2017.51

[104] A. Galletta, S. Allam, L. Carnevale, M. A. Bekri, R. E. Ouahbi, and M. Villari, “An innovative methodology for big data visualization in oceanographic domain," Proceedings of the International Conference on Geoinformatics and Data Analysis, Prague Czech Republic, pp. 103-107, 2018. Available: https://doi.org/10.1145/3220228.3220238

[105] K. Agavanakis, P. G. Papageorgas, G. A. Vokas, D. Ampatis, and C. Salame, "Energy trading market evolution to the energy internet a feasibility review on the enabling internet of things (IoT) cloud technologies," Proceedings of the TMREES 2018, Beirut, Lebanon, p. 30077, 2018. Available: https://doi.org/10.1063/1.5039264

[106] H. Pargmann, D. Euhausen, and R. Faber, "Intelligent big data processing for wind farm monitoring and analysis based on cloud-technologies and digital twins: A quantitative approach," IEEE 3rd International Conference on Cloud Computing and Big Data Analysis (ICCCBDA), Chengdu, pp. 233-237, 2018. Available: https://doi.org/10.1109/ICCCBDA.2018.8386518

[107] H. Lin et al., "Research on designing an integrated electric power marketing information system based on microapplications and microservices architecture," IEEE 3rd International Conference on Cloud Computing and Big Data Analysis (ICCCBDA), Chengdu, pp. 600-607, 2018. Available: https://doi.org/10.1109/ICCCBDA.2018.8386586

[108] R. Fu, F. Gao, R. Zeng, J. Hu, Y. Luo, and L. Qu, "Big data and cloud computing platform for energy Internet," China International Electrical and Energy Conference (CIEEC), Beijing, pp. 681-686, 2017. Available: https://doi.org/10.1109/CIEEC.2017.8388531

[109] S. K. Garg and J. Lakshmi, "Workload performance and interference on containers," IEEE SmartWorld, Ubiquitous Intelligence \& Computing, Advanced \& Trusted Computed, Scalable Computing \& Communications, Cloud \& Big Data Computing, Internet of People and Smart City Innovation (SmartWorld/SCALCOM/UIC/ATC/CBDCom/IOP/SCI), San Francisco, CA, pp. 1-6, 2017. Available: https://doi.org/10.1109/UIC-ATC.2017.8397647

[110] C. Simpkin, I. Taylor, G. A. Bent, G. de Mel, and S. Rallapalli, "Decentralized microservice workflows for coalition environments," IEEE SmartWorld, Ubiquitous Intelligence \& Computing, Advanced \& Trusted Computed, Scalable Computing \& Communications, Cloud \& Big Data Computing, Internet of People and 
Smart City Innovation (SmartWorld/SCALCOM/UIC/ATC/CBDCom/IOP/SCI), San Francisco, CA, pp. 1-7, 2017. Available: https://doi.org/10.1109/UIC-ATC.2017.8397424

[111] J. Liu et al., "A Generic and Highly Scalable Framework for the Automation and Execution of Scientific Data Processing and Simulation Workflows," IEEE 15th International Conference on Software Architecture: ICSA 2018, Seattle, WA, pp. 145-14510, 2018. Available: https://doi.org/10.1109/ICSA.2018.00024

[112] M. Artac, T. Borovsak, E. Di Nitto, M. Guerriero, D. Perez-Palacin, and D. A. Tamburri, "Infrastructure-asCode for Data-Intensive Architectures: A Model-Driven Development Approach," IEEE 15th International Conference on Software Architecture: ICSA 2018, Seattle, WA, pp. 156-15609, 2018. Available: https://doi.org/10.1109/ICSA.2018.00025

[113] R. Dooley, S. R. Brandt, and J. Fonner, "The Agave Platform: An Open, Science-as-a-Service Platform for Digital Science," Proceedings of the Practice and Experience on Advanced Research Computing, Pittsburgh PA USA, pp. 1-8, 2018. Available: https://doi.org/10.1145/3219104.3219129

[114] R. K. Naha et al., "Fog Computing: Survey of Trends, Architectures, Requirements, and Research Directions," IEEE Access, vol. 6, pp. 47980-48009, 2018. Available: https://doi.org/10.1109/ACCESS.2018.2866491

[115] I. Simonis, "Container-based architecture to optimize the integration of microservices into cloud-based dataintensive application scenarios," Proceedings of the 12th European Conference on Software Architecture: Companion Proceedings, Madrid, Spain, pp. 1-3, 2018. Available: https://doi.org/10.1145/3241403.3241439

[116] J. Herman, H. Herman, M. J. Mathews, and J. C. Vosloo, "Using big data for insights into sustainable energy consumption in industrial and mining sectors," Journal of Cleaner Production, vol. 197, pp. 1352-1364, 2018. Available: https://doi.org/10.1016/j.jclepro.2018.06.290

[117] A. Galletta, L. Carnevale, A. Buzachis, A. Celesti, and M. Villari, "A Microservices-Based Platform for Efficiently Managing Oceanographic Data," 4th International Conference on Big Data Innovations and Applications (Innovate-Data), Barcelona, pp. 25-29, 2018. Available: https://doi.org/10.1109/InnovateData.2018.00011

[118] M. García-Valls, A. Dubey, and V. Botti, "Introducing the new paradigm of Social Dispersed Computing: Applications, Technologies and Challenges," Journal of Systems Architecture, vol. 91, pp. 83-102, 2018. Available: https://doi.org/10.1016/j.sysarc.2018.05.007

[119] A. Zimmermann, R. Schmidt, K. Sandkuhl, D. Jugel, J. Bogner, and M. Mohring, "Evolution of Enterprise Architecture for Digital Transformation," IEEE 22nd International Enterprise Distributed Object Computing Conference workshops: EDOCW 2018, Stockholm, Sweden, pp. 87-96, 2018. Available: https://doi.org/10.1109/EDOCW.2018.00023

[120] A. Magalhaes, L. Rech, R. Moraes, and F. Vasques, "REPO: A Microservices Elastic Management System for Cost Reduction in the Cloud," IEEE Symposium on Computers and Communications (ISCC), Natal, pp. 328-333, 2018. Available: https://doi.org/10.1109/ISCC.2018.8538453

[121] W. Fan, Z. Han, Y. Zhang, and R. Wang, "Method of Maintaining Data Consistency in Microservice Architecture," IEEE 4th International Conference on Big Data Security on Cloud (BigDataSecurity), IEEE International Conference on High Performance and Smart Computing, (HPSC) and IEEE International Conference on Intelligent Data and Security (IDS), Omaha, NE, pp. 47-50, 2018. Available: https://doi.org/10.1109/BDS/HPSC/IDS18.2018.00023

[122] N. Parekh, S. Kurunji, and A. Beck, "Measuring Resources and Workload Skew In Micro-service MPP Analytic Query Engine," 14th International Conference on Information Processing (ICINPRO), Bangalore, India, pp. 1-6, 2018. Available: https://doi.org/10.1109/ICINPRO43533.2018.9096695

[123] T. H. Vu, N. H. B. Dai, H. N. T. Khanh, and D. N. V. Quang, "Overall Structural System Solution for Supporting Services and Tourists Management Oriented on Smart City in Viet Nam," Proceedings of the 9th International Symposium on Information and Communication Technology - SoICT 2018, Danang City, Viet Nam, pp. 430-435, 2018. Available: https://doi.org/10.1145/3287921.3287966

[124] Y. Zhai, W. Sun, T. Bao, K. Yang, and D. Qing, "Edge-side Simulation Method and Framework Based on Micro-services," Journal of System Simulation, vol. 30, no. 12, pp. 4536-4545, 2018. Available: https://doi.org/10.16182/j.issn1004731x.joss.201812006

[125] K. Lillaney et al., "Building NDStore Through Hierarchical Storage Management and Microservice Processing," IEEE 14th International Conference on e-Science (e-Science), Amsterdam, pp. 223-233, 2018. Available: https://doi.org/10.1109/eScience.2018.00037

[126] L. Gao, Q. Li, Y. Lian, P. Lv, and W. Zhou, "Unified Searching Service for Electric Big Data," Procedia Computer Science, vol. 162, pp. 123-130, 2019. Available: https://doi.org/10.1016/j.procs.2019.11.267 
[127] J. M. Alves, L. M. Honorio, and M. A. M. Capretz, "ML4IoT: A Framework to Orchestrate Machine Learning Workflows on Internet of Things Data," IEEE Access, vol. 7, pp. 152953-152967, 2019. Available: https://doi.org/10.1109/ACCESS.2019.2948160

[128] G. Ortiz, J. A. Caravaca, A. Garcia-de-Prado, F. La Chavez de O, and J. Boubeta-Puig, "Real-Time ContextAware Microservice Architecture for Predictive Analytics and Smart Decision-Making," IEEE Access, vol. 7, pp. 183177-183194, 2019. Available: https://doi.org/10.1109/ACCESS.2019.2960516

[129] A. Zimmermann, R. Schmidt, K. Sandkuhl, and D. Jugel, "Intelligent Decision Management for Architecting Service-Dominant Digital Products,” Procedia Computer Science, vol. 159, pp. 2120-2129, 2019. Available: https://doi.org/10.1016/j.procs.2019.09.385

[130] Y. Y. Fridelin, M. R. Ulil Albaab, A. R. Anom Besari, S. Sukaridhoto, and A. Tjahjono, "Implementation of Microservice Architectures on SEMAR Extension for Air Quality Monitoring," International Electronics Symposium on Knowledge Creation and Intelligent Computing (IES-KCIC), Bali, Indonesia, pp. 218-224, 2018. Available: https://doi.org/10.1109/KCIC.2018.8628575

[131] T. Branzov, K. Ivanova, and M. Georgiev, "Service-Microservice Basic System Architecture Model for Geoinformation Centres," 19th International Multidisciplinary Scientific GeoConference SGEM2019, Informatics, Geoinformatics and Remote Sensing, $2019 . \quad$ Available: https://doi.org/10.5593/sgem2019/2.1/S07.077

[132] A. Zimmermann, R. Schmidt, K. Sandkuhl, D. Jugel, J. Bogner, and M. Möhring, “Architecting ServiceDominant Digital Products," Communications in Computer and Information Science, Evaluation of Novel Approaches to Software Engineering, E. Damiani, G. Spanoudakis, and L. A. Maciaszek, eds., Springer, pp. 45-67, 2019. Available: https://doi.org/10.1007/978-3-030-22559-9_3

[133] W. Wang, L. Fan, P. Huang, and H. Li, "A New Data Processing Architecture for Multi-Scenario Applications in Aviation Manufacturing," IEEE Access, vol. 7, pp. 83637-83650, 2019. Available: https://doi.org/10.1109/ACCESS.2019.2925114

[134] S. Boulkaboul, D. Djenouri, S. Bouhafs, and M. Belaid, "IoT-DMCP: An IoT Data Management and Control Platform for Smart Cities," Proceedings of the 9th International Conference on Cloud Computing and Services Science, Heraklion, Crete, Greece, pp. 578-583, $2019 . \quad$ Available: https://doi.org/10.5220/0007861005780583

[135] A. Zimmermann, R. Schmidt, and K. Sandkuhl, "Multiple Perspectives of Digital Enterprise Architecture," Proceedings of the 14th International Conference on Evaluation of Novel Approaches to Software Engineering, Heraklion, Crete, Greece, pp. 547-554, $2019 . \quad$ Available: https://doi.org/10.5220/0007769105470554

[136] A. Sadlier and J. Jerry, "Implementing the real-time data environment for the oil and gas digital transformation," Proceedings of the Offshore Mediterranean Conference and Exhibition 2019, Ravenna, Italy, 2019.

[137] E. Sudheer Kumar and C. Shoba Bindu, "Medical Image Analysis Using Deep Learning: A Systematic Literature Review," Communications in Computer and Information Science, Emerging Technologies in Computer Engineering: Microservices in Big Data Analytics, A. K. Somani, S. Ramakrishna, A. Chaudhary, C. Choudhary, and B. Agarwal, eds., Springer, pp. 81-97, 2019. Available: https://doi.org/10.1007/978-98113-8300-7_8

[138] S. B. B. Priyadarshini, A. Bhusan Bagjadab, and B. K. Mishra, "The Role of IoT and Big Data in Modern Technological Arena: A Comprehensive Study," Intelligent Systems Reference Library, Internet of Things and Big Data Analytics for Smart Generation, V. E. Balas, V. K. Solanki, R. Kumar, and M. Khari, eds., Springer, pp. 13-25, 2019. Available: https://doi.org/10.1007/978-3-030-04203-5_2

[139] N. Parekh, S. Kurunji, and A. Beck, "Monitoring Resources of Machine Learning Engine In Microservices Architecture," IEEE 9th Annual Information Technology, Electronics and Mobile Communication Conference (IEMCON), Vancouver, Canada, pp. 486-492, 2018. Available: https://doi.org/10.1109/IEMCON.2018.8614791

[140] A. Kaplunovich and Y. Yesha, "Consolidating billions of Taxi rides with AWS EMR and Spark in the Cloud : Tuning, Analytics and Best Practices," IEEE International Conference on Big Data (Big Data), Seattle, WA, USA, pp. 4501-4507, 2018. Available: https://doi.org/10.1109/BigData.2018.8622378

[141] C. Streiffer, R. Raghavendra, T. Benson, and M. Srivatsa, "Learning to Simplify Distributed Systems Management," IEEE International Conference on Big Data (Big Data), Seattle, WA, USA, pp. 1837-1845, 2018. Available: https://doi.org/10.1109/BigData.2018.8622058

[142] H. Tianfield, “Towards Edge-Cloud Computing," IEEE International Conference on Big Data (Big Data), Seattle, WA, USA, pp. 4883-4885, 2018. Available: https://doi.org/10.1109/BigData.2018.8622052 
[143] E. Al-Masri, "Enhancing the Microservices Architecture for the Internet of Things," IEEE International Conference on Big Data (Big Data), Seattle, WA, USA, pp. 5119-5125, 2018. Available: https://doi.org/10.1109/BigData.2018.8622557

[144] O. Qayyum and M. Sah, "IOS Mobile Application for Food and Location Image Prediction using Convolutional Neural Networks," IEEE 5th International Conference on Engineering Technologies and Applied Sciences (ICETAS), Bangkok, Thailand, pp. 1-6, 2018. Available: https://doi.org/10.1109/ICETAS.2018.8629202

[145] T. Pradeep Pai and K. L. Shashikala, "Smart City Services - Challenges and Approach," International Conference on Machine Learning, Big Data, Cloud and Parallel Computing (COMITCon), Faridabad, India, pp. 553-558, 2019. Available: https://doi.org/10.1109/COMITCon.2019.8862243

[146] D. Sik, K. Csorba, and P. Ekler, "Toward Cognitive Data Analysis with Big Data Environment," 9th IEEE International Conference on Cognitive Infocommunications (CogInfoCom), Budapest, Hungary, pp. 23-28, 2018. Available: https://doi.org/10.1109/CogInfoCom.2018.8639948

[147] A. Javed, N. Yousefnezhad, J. Robert, K. Heljanko, and K. Framling, "Access Time Improvement Framework for Standardized IoT Gateways," IEEE International Conference on Pervasive Computing and Communications Workshops (PerCom Workshops), Kyoto, Japan, pp. 220-226, 2019. Available: https://doi.org/10.1109/PERCOMW.2019.8730867

[148] Z. Li, D. Seco, and A. E. Sánchez Rodríguez, "Microservice-Oriented Platform for Internet of Big Data Analytics: A Proof of Concept,” Sensors, vol. 19, no. 5, 2019. Available: https://doi.org/10.3390/s19051134

[149] G. Kiar, S. T. Brown, T. Glatard, and A. C. Evans, “A Serverless Tool for Platform Agnostic Computational Experiment Management," Frontiers in Neuroinformatics, vol. 13, p. 12, 2019. Available: https://doi.org/10.3389/fninf.2019.00012

[150] K. A. Torkura, M. I. Sukmana, A. V. Kayem, F. Cheng, and C. Meinel, “A Cyber Risk Based Moving Target Defense Mechanism for Microservice Architectures," IEEE Intl Conf on Parallel \& Distributed Processing with Applications, Ubiquitous Computing \& Communications, Big Data \& Cloud Computing, Social Computing \& Networking, Sustainable Computing \& Communications (ISPA/IUCC/BDCloud/SocialCom/SustainCom), Melbourne, Australia, pp. 932-939, 2018. Available: https://doi.org/10.1109/BDCloud.2018.00137

[151] S. Sarkar and S. Venkateswaran, "Best-Fit Containerization as a Brokered Service," IEEE Intl Conf on Parallel \& Distributed Processing with Applications, Ubiquitous Computing \& Communications, Big Data \& Cloud Computing, Social Computing \& Networking, Sustainable Computing \& Communications (ISPA/IUCC/BDCloud/SocialCom/SustainCom), Melbourne, Australia, pp. 940-947, 2018. Available: https://doi.org/10.1109/BDCloud.2018.00138

[152] Q. Lei, W. Liao, Y. Jiang, M. Yang, and H. Li, "Performance and Scalability Testing Strategy Based on Kubemark," IEEE 4th International Conference on Cloud Computing and Big Data Analysis (ICCCBDA), Chengdu, China, pp. 511-516, 2019. Available: https://doi.org/10.1109/ICCCBDA.2019.8725658

[153] S. Zhang, M. Zhang, L. Ni, and P. Liu, "A Multi-Level Self-Adaptation Approach For Microservice Systems," IEEE 4th International Conference on Cloud Computing and Big Data Analysis (ICCCBDA), Chengdu, China, pp. 498-502, 2019. Available: https://doi.org/10.1109/ICCCBDA.2019.8725647

[154] H. S. Chiranjeevi and K. S. Manjula, “An Text Document Retrieval System for University Support Service on a High Performance Distributed Information System," IEEE 4th International Conference on Cloud Computing and Big Data Analysis (ICCCBDA), Chengdu, China, pp. 50-54, 2019. Available: https://doi.org/10.1109/ICCCBDA.2019.8725768

[155] A. M. D. Esposte et al., "Design and evaluation of a scalable smart city software platform with large-scale simulations," Future Generation Computer Systems, vol. 93, pp. 427-441, 2019. Available: https://doi.org/10.1016/j.future.2018.10.026

[156] Y. Gan et al., "Seer: Leveraging Big Data to Navigate the Complexity of Performance Debugging in Cloud Microservices," Proceedings of the Twenty-Fourth International Conference on Architectural Support for Programming Languages and Operating Systems, Providence RI USA, pp. 19-33, 2019. Available: https://doi.org/10.1145/3297858.3304004

[157] D. Chen, M. Gao, A. Liu, M. Chen, Z. Zhang, and Y. Feng, “A Recurrent Neural Network Based Approach for Web Service QoS Prediction," 2nd International Conference on Artificial Intelligence and Big Data (ICAIBD), Chengdu, China, pp. 350-357, 2019. Available: https://doi.org/10.1109/ICAIBD.2019.8837006

[158] F. Pop and V. Cristea, "Distributed Systems Education: From Traditional Models to New Paths of Learning," 22nd International Conference on Control Systems and Computer Science (CSCS), Bucharest, Romania, pp. 383-386, 2019. Available: https://doi.org/10.1109/CSCS.2019.00070 
[159] P. Lin, Z. Lin, and X. Shi, "Research on Optimization of Course Selection System Based on Micro service and Dynamic Resource Extension," Proceedings of the 2019 4th International Conference on Big Data and Computing - ICBDC 2019, Guangzhou, China, pp. 115-119, $2019 . \quad$ Available: https://doi.org/10.1145/3335484.3335546

[160] S. Henning, W. Hasselbring, and A. Mobius, “A Scalable Architecture for Power Consumption Monitoring in Industrial Production Environments," IEEE International Conference on Fog Computing (ICFC), Prague, Czech Republic, pp. 124-133, 2019. Available: https://doi.org/10.1109/ICFC.2019.00024

[161] P. Kochovski, M. Bajec, R. Sakellariou, and V. Stankovski, "A Smart and Safe Construction Application Design for Fog Computing," IEEE World Congress on Services (SERVICES), Milan, Italy, pp. 378-379, 2019. Available: https://doi.org/10.1109/SERVICES.2019.00112

[162] S. Fernando, D. Birch, M. Molina-Solana, D. Mcilwraith, and Y. Guo, "Compositional Microservices for Immersive Social Visual Analytics," 23rd International Conference Information Visualisation (IV), Paris, France, pp. 216-223, 2019. Available: https://doi.org/10.1109/IV.2019.00044

[163] D. Profeta, N. Masi, D. Messina, D. Dalle Carbonare, S. Bonura, and V. Morreale, "A Novel Micro-Service Based Platform for Composition, Deployment and Execution of BDA Applications," 45th Euromicro Conference on Software Engineering and Advanced Applications (SEAA), Kallithea-Chalkidiki, Greece, pp. 182-185, 2019. Available: https://doi.org/10.1109/SEAA.2019.00037

[164] H. Hu et al., "TopoLens: Building a CyberGIS community data service for enhancing the usability of high-resolution national topographic datasets," Concurrency Computat Pract Exper, 2018. Available: https://doi.org/10.1002/cpe.4682

[165] X. Bin, Z. Bo, Z. Xiangdong, G. Yongming, and L. Liang, "Research and Application of Micro-service Platform Based on Ubiquitous Power Internet of Things," Proceedings of the 2nd International Conference on Big Data Technologies - ICBDT2019, Jinan, China, pp. 24-28, 2019. Available: https://doi.org/10.1145/3358528.3358576

[166] A. Beheshti, B. Benatallah, A. Tabebordbar, H. R. Motahari-Nezhad, M. C. Barukh, and R. Nouri, "DataSynapse: A Social Data Curation Foundry," Distrib Parallel Databases, vol. 37, no. 3, pp. 351-384, 2019. Available: https://doi.org/10.1007/s10619-018-7245-1

[167] J. L. Ribeiro, M. Figueredo, A. Araujo, N. Cacho, and F. Lopes, "A Microservice Based Architecture Topology for Machine Learning Deployment," IEEE International Smart Cities Conference (ISC2), Casablanca, Morocco, pp. 426-431, 2019. Available: https://doi.org/10.1109/ISC246665.2019.9071708

[168] T.-H. Jeng, W.-M. Chan, W.-Y. Luo, C.-C. Huang, C.-C. Chen, and Y.-M. Chen, "NetFlowTotal: A cloud service integration platform for malicious traffic analysis and collaboration," Proceedings of the 2nd International Conference on Computing and Big Data - ICCBD 2019, Taichung, Taiwan, pp. 154-160, 2019. Available: https://doi.org/10.1145/3366650.3366669

[169] Z. Li and E. J. Pino, "D\&D: A Distributed and Disposable Approach to Privacy Preserving Data Analytics in User-Centric Healthcare," IEEE 12th Conference on Service-Oriented Computing and Applications (SOCA), Kaohsiung, Taiwan, pp. 176-183, 2019. Available: https://doi.org/10.1109/SOCA.2019.00033

[170] S. Zhelev and A. Rozeva, "Using microservices and event driven architecture for big data stream processing," Proceedings of the 45th International Conference on Application of mathematics in engineering and economics (AMEE'19), Sozopol, Bulgaria, p. 90010, 2019. Available: https://doi.org/10.1063/1.5133587

[171] S. B. Popov and P. V. Khripunov, "Digital Transformation Legacy Social Service Information System," J. Phys.: Conf. Ser., vol. 1368, p. 52019, 2019. Available: https://doi.org/10.1088/1742-6596/1368/5/052019

[172] U. Wajid, C. Orton, A. Magdalinou, and L. Montandon, "Generating and Knowledge Framework: Design and Open Specification," Acta Informatica Medica : AIM : Journal of the Society for Medical Informatics of Bosnia \& Herzegovina : casopis Drustva za medicinsku informatiku BiH, vol. 27, no. 5, pp. 362-368, 2019. Available: https://doi.org/10.5455/aim.2019.27.362-368

[173] Y. Zhang, Y. Liu, B. Li, and L. Li, "Research on Distribution Network Status Management System Based on Cloud Platform," International Joint Conference on Information, Media and Engineering (IJCIME), Osaka, Japan, pp. 391-395, 2019. Available: https://doi.org/10.1109/IJCIME49369.2019.00085

[174] A. de Iasio, A. Futno, L. Goglia, and E. Zimeo, “A Microservices Platform for Monitoring and Analysis of IoT Traffic Data in Smart Cities," IEEE International Conference on Big Data (Big Data), Los Angeles, CA, USA, pp. 5223-5232, 2019. Available: https://doi.org/10.1109/BigData47090.2019.9006025

[175] D. H. Ho, R. Marri, S. Rella, and Y. Lee, "DeepLite: Real-Time Deep Learning Framework for Neighborhood Analysis," IEEE International Conference on Big Data (Big Data), Los Angeles, CA, USA, pp. 5673-5678, 2019. Available: https://doi.org/10.1109/BigData47090.2019.9005651 
[176] D. Goel and A. Nayak, "Reactive Microservices in Commodity Resources," IEEE International Conference on Big Data (Big Data), Los Angeles, CA, USA, pp. 3658-3665, 2019. Available: https://doi.org/10.1109/BigData47090.2019.9006584

[177] H. Chegini and A. Mahanti, "A Framework of Automation on Context-Aware Internet of Things (IoT) Systems," Proceedings of the 12th IEEE/ACM International Conference on Utility and Cloud Computing Companion - UCC'19 Companion, Auckland, New Zealand, pp. 157-162, 2019. Available: https://doi.org/10.1145/3368235.3368848

[178] V. Nagendra, V. Yegneswaran, P. Porras, and S. R. Das, "Coordinated dataflow protection for ultra-high bandwidth science networks," Proceedings of the 35th Annual Computer Security Applications Conference, San Juan Puerto Rico USA, pp. 568-583, 2019. Available: https://doi.org/10.1145/3359789.3359843

[179] Q. Liu, X. Liu, and P. Zhao, "Construction of Smart City Spatio-Temporal Information Cloud Platform in Weifang, China,” Journal of Donghua University (English Edition), vol. 36, no. 6, pp. 615-622, 2019.

[180] J. Sousa, J. Ferreira, C. Lopes, J. Sarraipa, and J. Silva, "Enhancing the Steel Tube Manufacturing Process With a Zero Defects Approach," ASME 2020 International Mechanical Engineering Congress and Exposition, Volume 2B: Advanced Manufacturing, 2020. Available: https://doi.org/10.1115/IMECE202024678

[181] A. Galletta and M. Villari, "How to Manage Efficiently Clinical Big-Data by Means of Cloud Computing," Service-Oriented and Cloud Computing, Como, Italy, pp. 148-157, 2021. Available: https://doi.org/10.1007/978-3-030-63161-1_12

[182] Z. Tang et al., "Research and application of improving the field service ability of electric power marketing measuring mobile operating based on cloud computing technology," IJHPSA, vol. 9, no. 2/3, p. 117, 2020. Available: https://doi.org/10.1504/IJHPSA.2020.111563

[183] Z. Du et al., "Construction of a campus Q\&A platform based on big data and microservice architecture," $J$. Phys.: Conf. Ser., vol. 1682, p. 12051, 2020. Available: https://doi.org/10.1088/1742-6596/1682/1/012051

[184] L. Zhu and S. Wang, "An Artificial Intelligent and Big Data Research Platform Based on Jupyter Notebook," Proceedings of the 10th International Workshop on Computer Science and Engineering, 2020. Available: https://doi.org/10.18178/wcse.2020.06.070

[185] S. Shahoud, S. Gunnarsdottir, H. Khalloof, C. Duepmeier, and V. Hagenmeyer, "Facilitating and Managing Machine Learning and Data Analysis Tasks in Big Data Environments Using Web and Microservice Technologies," Lecture Notes in Computer Science, Transactions on Large-Scale Data- and KnowledgeCentered Systems XLV, A. Hameurlain et al., eds., Springer, pp. 132-171, 2020. Available: https://doi.org/10.1007/978-3-662-62308-4_6

[186] H. Khazaei, R. Ravichandiran, B. Park, H. Bannazadeh, A. Tizghadam, and A. Leon-Garcia, "Elascale: autoscaling and monitoring as a service," CASCON '17: Proceedings of the 27th Annual International Conference on Computer Science and Software Engineering, Ontario, Canada, pp. 234-240, 2017.

[187] L. Tang, H. Hu, Z. Wang, J. Wang, and Y. Li, "Microservice Architecture Design for Big Data in Tactical Cloud," Communications in Computer and Information Science, Big Data and Security, Y. Tian, T. Ma, and M. K. Khan, eds., Springer, pp. 402-416, 2020. Available: https://doi.org/10.1007/978-981-15-7530-3_31

[188] H. Calderon-Gomez et al., "Telemonitoring System for Infectious Disease Prediction in Elderly People Based on a Novel Microservice Architecture," IEEE Access, vol. 8, pp. 118340-118354, 2020. Available: https://doi.org/10.1109/ACCESS.2020.3005638

[189] F. Gand, I. Fronza, N. El Ioini, H. Barzegar, and C. Pahl, "Serverless Container Cluster Management for Lightweight Edge Clouds," Proceedings of the 10th International Conference on Cloud Computing and Services Science, Prague, Czech Republic, pp. 302-311, 2020. Available: https://doi.org/10.5220/0009379503020311

[190] Y. Jiang, N. Zhang, and Z. Ren, "Research on Intelligent Monitoring Scheme for Microservice Application Systems," International Conference on Intelligent Transportation, Big Data \& Smart City (ICITBS), Vientiane, Laos, pp. 791-794, 2020. Available: https://doi.org/10.1109/ICITBS49701.2020.00173

[191] P. Zhao, P. Wang, X. Yang, and J. Lin, "Towards Cost-Efficient Edge Intelligent Computing With Elastic Deployment of Container-Based Microservices," IEEE Access, vol. 8, pp. 102947-102957, 2020. Available: https://doi.org/10.1109/ACCESS.2020.2998767

[192] J. Gao, W. Li, Z. Zhao, and Y. Han, "Provisioning big data applications as services on containerised cloud: a microservices-based approach," IJSTM, vol. 26, no. 2/3, p. 167, 2020. Available: https://doi.org/10.1504/IJSTM.2020.106744 
[193] S. Rabinovici-Cohen et al., "Radiomics for predicting response to neoadjuvant chemotherapy treatment in breast cancer," Medical Imaging 2020: Imaging Informatics for Healthcare, Research, and Applications, Houston, United States, p. 45, 2020. Available: https://doi.org/10.1117/12.2551374

[194] J. Sidler, E. Braun, T. Schlachter, C. Düpmeier, and V. Hagenmeyer, "Design of a Web-Service for Formal Descriptions of Domain-Specific Data," IFIP Advances in Information and Communication Technology, Environmental Software Systems. Data Science in Action, I. N. Athanasiadis, S. P. Frysinger, G. Schimak, and W. J. Knibbe, eds., Springer, pp. 201-215, 2020. Available: https://doi.org/10.1007/978-3-030-398156_20

[195] P. Patros, K. B. Kent, and M. H. Dawson, "SLO request modeling, reordering and scaling," Proceedings of the 27th Annual International Conference on Computer Science and Software Engineering, Toronto, Canada, pp. 180-191, 2017.

[196] J. Zhao and J. Sun, "Research on Access Control Model Based on RBAC Model in Microservice Environment," J. Phys.: Conf. Ser., vol. 1437, p. 12031, 2020. Available: https://doi.org/10.1088/17426596/1437/1/012031

[197] Y. Liu, J. Huang, and N. Lu, "Research on Environmental Monitoring System Based on Microservices and Data Mining,” E3S Web Conf., vol. 143, 2020. Available: https://doi.org/10.1051/e3sconf/202014302031

[198] J. Yao and X. Jiang, "Research on multi cloud dynamic secure storage technology," International Conference on Computer Engineering and Application (ICCEA), Guangzhou, China, pp. 72-78, 2020. Available: https://doi.org/10.1109/ICCEA50009.2020.00022

[199] L. Butgereit, "Big Data and Machine Learning for Forestalling Customer Churn Using Hybrid Software," Conference on Information Communications Technology and Society (ICTAS), Durban, South Africa, pp. 14, 2020. Available: https://doi.org/10.1109/ICTAS47918.2020.233972

[200] F. Neves, R. Vilaça, and J. Pereira, "Black-box inter-application traffic monitoring for adaptive container placement," Proceedings of the 35th Annual ACM Symposium on Applied Computing, Brno, Czech Republic, pp. 259-266, 2020. Available: https://doi.org/10.1145/3341105.3374007

[201] K. Li, Y. Ding, D. Shen, Q. Li, and Z. Zhen, "The Design and Research of Front-End Framework for Microservice Environment," International Conference on Computer Information and Big Data Applications (CIBDA), Guiyang, China, pp. 124-127, 2020. Available: https://doi.org/10.1109/CIBDA50819.2020.00036

[202] K. Li, Y. Ding, X. Li, X. He, W. Zhang, and W. Li, "Security Management System Construction of Information System Based on Big Data Analysis," International Conference on Urban Engineering and Management Science (ICUEMS), Zhuhai, China, pp. 546-549, 2020. Available: https://doi.org/10.1109/ICUEMS50872.2020.00120

[203] T. Lv, J. Zhang, and Y. Chen, "Research on Diabetes Management Platform Based on Big Data Technology," 3rd International Conference on Advanced Electronic Materials, Computers and Software Engineering (AEMCSE), Shenzhen, China, pp. 434-437, $2020 . \quad$ Available: https://doi.org/10.1109/AEMCSE50948.2020.00100

[204] W. Li, C. Feng, K. Yu, and D. Zhao, "MISS-D: A fast and scalable framework of medical image storage service based on distributed file system," Computer Methods and Programs in Biomedicine, vol. 186, p. 105189, 2020. Available: https://doi.org/10.1016/j.cmpb.2019.105189

[205] X. Liang and Q. Zhao, "On the Design of a Blockchain-based Student Quality Assessment System," International Conference on High Performance Big Data and Intelligent Systems (HPBD\&IS), Shenzhen, China, pp. 1-7, 2020. Available: https://doi.org/10.1109/HPBDIS49115.2020.9130584

[206] K. Feng, J. Zhou, Y. Liu, F. He, Z. he, and B. Jia, “A construction method of water conservancy model library based on Microservice," IOP Conf. Ser.: Mater. Sci. Eng., vol. 794, p. 12001, 2020. Available: https://doi.org/10.1088/1757-899X/794/1/012001

[207] H. Lv, T. Zhang, Z. Zhao, J. Xu, and T. He, "The Development of Real-time Large Data Processing Platform Based On Reactive Micro-Service Architecture," IEEE 4th Information Technology, Networking, Electronic and Automation Control Conference (ITNEC), Chongqing, China, pp. 2003-2006, 2020. Available: https://doi.org/10.1109/ITNEC48623.2020.9084717

[208] A. Razzaq, "Microservices Architecture for IoT Applications in the Ocean : Microservices Architecture based Framework for Reducing the Complexity and Increasing the Scalability of IoT Applications in the Ocean," 20th International Conference on Computational Science and Its Applications (ICCSA), Cagliari, Italy, pp. 87-90, 2020. Available: https://doi.org/10.1109/ICCSA50381.2020.00025

[209] I. Salvadori, A. Huf, and F. Siqueira, "Data Linking as a Service: An Infrastructure for Generating and Publishing Linked Data on the Web," IEEE 44th Annual Computers, Software, and Applications Conference 
(COMPSAC), Madrid, Spain, pp. 262-271, 2020. Available: https://doi.org/10.1109/COMPSAC48688.2020.00042

[210] R. Cordingly et al., "Implications of Programming Language Selection for Serverless Data Processing Pipelines," IEEE Intl Conf on Dependable, Autonomic and Secure Computing, Intl Conf on Pervasive Intelligence and Computing, Intl Conf on Cloud and Big Data Computing, Intl Conf on Cyber Science and Technology Congress (DASC/PiCom/CBDCom/CyberSciTech), Calgary, AB, Canada, pp. 704-711, 2020. Available: https://doi.org/10.1109/DASC-PICom-CBDCom-CyberSciTech49142.2020.00120

[211] R. Laigner et al., "From a Monolithic Big Data System to a Microservices Event-Driven Architecture," 46th Euromicro Conference on Software Engineering and Advanced Applications (SEAA), Portoroz, Slovenia, pp. 213-220, 2020. Available: https://doi.org/10.1109/SEAA51224.2020.00045

[212] Y. Gong, F. Gu, K. Chen, and F. Wang, "The Architecture of Micro-services and the Separation of Frondend and Back-end Applied in a Campus Information System," IEEE International Conference on Advances in Electrical Engineering and Computer Applications( AEECA), Dalian, China, pp. 321-324, 2020. Available: https://doi.org/10.1109/AEECA49918.2020.9213662

[213] K. Milkovich, S. Shirur, P. K. Desai, L. Manjunath, and W. Wu, "ZenDen - A Personalized House Searching Application," IEEE Sixth International Conference on Big Data Computing Service and Applications (BigDataService), Oxford, United Kingdom, pp. 173-178, 2020. Available: https://doi.org/10.1109/BigDataService49289.2020.00034

[214] A. Chouhan, A. Prabhune, P. Prabhuraj, and H. Chaudhari, "DWreck: A Data Wrecker Framework for Generating Unclean Datasets," IEEE Sixth International Conference on Big Data Computing Service and Applications (BigDataService), Oxford, United Kingdom, pp. 78-87, 2020. Available: https://doi.org/10.1109/BigDataService49289.2020.00020

[215] K. Li, Y. Ding, Y. Shi, L. Wang, and Z. Zhen, "Research and Application of High-Performance Data Storage and Transmission Technology in Microservice Environment," J. Phys.: Conf. Ser., vol. 1616, p. 12092, 2020. Available: https://doi.org/10.1088/1742-6596/1616/1/012092

[216] Z. Wang, Y. Xia, C. Sun, and L. Cheng, "Research on Microservice Application Performance Monitoring Framework and Elastic Scaling Mode," J. Phys.: Conf. Ser., vol. 1617, p. 12048, 2020. Available: https://doi.org/10.1088/1742-6596/1617/1/012048

[217] S. P. R. Asaithambi, R. Venkatraman, and S. Venkatraman, "MOBDA: Microservice-Oriented Big Data Architecture for Smart City Transport Systems," BDCC, vol. 4, no. 3, p. 17, 2020. Available: https://doi.org/10.3390/bdcc4030017

[218] M. Alessi, A. Camillo, E. Giangreco, S. Pino, and D. Storelli, "A data visualization solution for the smart city to exploit environmental data by means of 3d buildings," 5th International Conference on Smart and Sustainable Technologies (SpliTech), Split, Croatia, pp. 1-7, 2020. Available: https://doi.org/10.23919/SpliTech49282.2020.9243831

[219] X. Chen, K. Wang, X. Su, and S. Zhan, "Design and Implementation of Technical Indicators Analysis System for Drilling Based on Microservices," International Conference on Big Data \& Artificial Intelligence \& Software Engineering (ICBASE), Bangkok, Thailand, pp. 233-236, 2020. Available: https://doi.org/10.1109/ICBASE51474.2020.00056

[220] T. Liang, "Design and Implementation of Big Data Visual Statistical Analysis Platform," 2nd International Conference on Machine Learning, Big Data and Business Intelligence (MLBDBI), Taiyuan, China, pp. 287291, 2020. Available: https://doi.org/10.1109/MLBDBI51377.2020.00061

[221] C. Hu et al., "TOPOSCH: Latency-Aware Scheduling Based on Critical Path Analysis on Shared YARN Clusters," IEEE 13th International Conference on Cloud Computing (CLOUD), Beijing, China, pp. 619-627, 2020. Available: https://doi.org/10.1109/CLOUD49709.2020.00091

[222] B. Tong et al., "The implementation of micro-service technology in the development of geohazard online analysis and evaluation," J. Phys.: Conf. Ser., vol. 1634, p. 12015, 2020. Available: https://doi.org/10.1088/1742-6596/1634/1/012015

[223] S. Shahoud, H. Khalloof, M. Winter, C. Duepmeier, and V. Hagenmeyer, "A Meta Learning Approach for Automating Model Selection in Big Data Environments using Microservice and Container Virtualization Technologies," Proceedings of the 12th International Conference on Management of Digital EcoSystems, Virtual Event United Arab Emirates, pp. 84-91, 2020. Available: https://doi.org/10.1145/3415958.3433072

[224] H. Zhu, I. Bayley, and H. Wang, "Continuous Debugging of Microservices," IEEE Intl Conf on Parallel \& Distributed Processing with Applications, Big Data \& Cloud Computing, Sustainable Computing \& Communications, Social Computing \& Networking (ISPA/BDCloud/SocialCom/SustainCom), Exeter, United 
Kingdom, pp. 736-745, 2020. Available: https://doi.org/10.1109/ISPA-BDCloud-SocialComSustainCom51426.2020.00118

[225] D. Liu, C. Li, Z. Jiang, R. Kong, L. Wu, and C. Ma, "Integrated Power Grid Management System based on Micro Service," 8th International Conference on Advanced Cloud and Big Data (CBD), Taiyuan, China, pp. 37-41, 2020. Available: https://doi.org/10.1109/CBD51900.2020.00016

[226] J. Bogatinovski, S. Nedelkoski, J. Cardoso, and O. Kao, "Self-Supervised Anomaly Detection from Distributed Traces," IEEE/ACM 13th International Conference on Utility and Cloud Computing (UCC), Leicester, UK, pp. 342-347, 2020. Available: https://doi.org/10.1109/UCC48980.2020.00054

[227] S. Roach et al., "CANON: Complex Analytics of Network of Networks for Modeling Adversarial Activities," Proceedings of the 2020 IEEE International Conference on Big Data (Big Data), Atlanta, GA, USA, pp. 1634-1643, 2020. Available: https://doi.org/10.1109/BigData50022.2020.9378258

[228] O. Tsilingeridis and A. Karakasidis, "MILMS: A Microservices-based Learning Management System," Proceedings of the 2020 IEEE International Conference on Big Data (Big Data), Atlanta, GA, USA, pp. 5843-5845, 2020. Available: https://doi.org/10.1109/BigData50022.2020.9378285

[229] L. Goglia and E. Zimeo, "Contact-Tracing based on Time-Varying Graphs Analysis," Proceedings of the 2020 IEEE International Conference on Big Data (Big Data), Atlanta, GA, USA, pp. 3190-3198, 2020. Available: https://doi.org/10.1109/BigData50022.2020.9377835

[230] M. Hamilton et al., "Large-Scale Intelligent Microservices," Proceedings of the 2020 IEEE International Conference on Big Data (Big Data), Atlanta, GA, USA, pp. 298-309, 2020. Available: https://doi.org/10.1109/BigData50022.2020.9378270

[231] C. Xu and W. Zhao, "Integrated platform of science and technology service resources under big data environment," Asia-Pacific Conference on Communications Technology and Computer Science (ACCTCS), Shenyang, China, pp. 80-84, 2021. Available: https://doi.org/10.1109/ACCTCS52002.2021.00024

[232] C.-H. Chang, T.-C. Hsu, W. C.-C. Chu, C.-L. Hung, and P.-F. Chiu, "A smart service warehousing platform supporting big data deep learning modeling analysis," Journal of Internet Technology, vol. 22, no. 2, pp. 483-489, 2021.

[233] F. A. Pontes and E. Curry, "Cloud-Edge Microservice Architecture for DNN-based Distributed Multimedia Event Processing," Communications in Computer and Information Science, Advances in Service-Oriented and Cloud Computing, C. Zirpins et al., eds., Springer, pp. 65-72, 2021. Available: https://doi.org/10.1007/978-3-030-71906-7_6

[234] P. Petrou, S. Karagiorgou, and D. Alexandrou, "Weighted load balancing mechanisms over streaming big data for online machine learning," Ceur Workshop Proceedings, vol. 2841, Nicosia, Cyprus, 2021.

[235] A. Malynov and I. Prokhorov, "Development of an AI Recommender System to Recommend Concerts Based on Microservice Architecture Using Collaborative and Content-Based Filtering Methods," Advances in Intelligent Systems and Computing, Brain-Inspired Cognitive Architectures for Artificial Intelligence: $B I C A * A I$ 2020, A. V. Samsonovich, R. R. Gudwin, and A. S. Da Simões, eds., Springer, pp. 241-252, 2021. Available: https://doi.org/10.1007/978-3-030-65596-9_31

[236] H. Khalloof, W. Jakob, S. Shahoud, C. Duepmeier, and V. Hagenmeyer, "A Generic Scalable Method for Scheduling Distributed Energy Resources Using Parallelized Population-Based Metaheuristics," Advances in Intelligent Systems and Computing, Proceedings of the Future Technologies Conference (FTC) 2020, vol. 2, K. Arai, S. Kapoor, and R. Bhatia, eds., Springer, pp. 1-21, 2021. Available: https://doi.org/10.1007/978-3030-63089-8_1

[237] B. Wadii, A. Boulmakoul, L. Karim, and A. Lbath, "Big Data Analytics Framework for Smart City RealTime Fuzzy Complex Event Processing," Advances in Intelligent Systems and Computing, Intelligent and Fuzzy Techniques: Smart and Innovative Solutions, C. Kahraman, S. Cevik Onar, B. Oztaysi, I. U. Sari, S. Cebi, and A. C. Tolga, eds., Springer, pp. 825-832, 2021. Available: https://doi.org/10.1007/978-3-03051156-2_95

[238] X. Wang and J. Gong, "Research and Design of Cloud Broadcasting System," 2nd International Conference on Computing and Data Science, Stanford, CA, USA, pp. 1-6, 2021. Available: https://doi.org/10.1145/3448734.3450454

[239] N. Singh, D. P. Singh, B. Pant, and U. K. Tiwari, " $\mu$ BIGMSA-Microservice-Based Model for Big Data Knowledge Discovery: Thinking Beyond the Monoliths," Wireless Pers Commun, 2020. Available: https://doi.org/10.1007/s11277-020-07822-0

[240] S. Xiong and B. Huang, "A Novel Think Tanks Evaluation System Based on Micro Service," J. Phys.: Conf. Ser., vol. 1757, no. 1, 2021. Available: https://doi.org/10.1088/1742-6596/1757/1/012197 
[241] X. Liu, H. Wang, H. Ma, L. Wang, and L. Wang, "The Architecture Design and Implementation of Aircraft Structural Fault Assistant Decision System Based on Data Analysis," J. Phys.: Conf. Ser., vol. 1813, no. 1, 2021. Available: https://doi.org/10.1088/1742-6596/1813/1/012032

[242] O. Tomarchio, D. Calcaterra, G. Di Modica, and P. Mazzaglia, "TORCH: a TOSCA-Based Orchestrator of Multi-Cloud Containerised Applications," J Grid Computing, vol. 19, no. 1, 2021. Available: https://doi.org/10.1007/s10723-021-09549-Z

[243] F. Z. Benchara and M. Youssfi, "A new scalable distributed k-means algorithm based on Cloud microservices for High-performance computing," Parallel Computing, vol. 101, 2021. Available: https://doi.org/10.1016/j.parco.2020.102736

[244] L. Qing, “A 5G PaaS Collaborative Management and Control Platform Technology Based on Cloud Edge Collaboration Based on Particle Swarm Optimization Algorithm," Proceedings of 2021 IEEE Asia-Pacific Conference on Image Processing, Electronics and Computers (IPEC), Dalian, China, pp. 144-147, 2021. Available: https://doi.org/10.1109/IPEC51340.2021.9421164

[245] S. Henning and W. Hasselbring, "Theodolite: Scalability Benchmarking of Distributed Stream Processing Engines in Microservice Architectures," Big Data Research, vol. 25, 2021. Available: https://doi.org/10.1016/j.bdr.2021.100209

[246] S. Kim, F. B. Bastani, I.-L. Yen, and I.-R. Chen, "High-assurance synthesis of security services from basic microservices," 14th International Symposium on Software Reliability Engineering, ISSRE 2003, Denver, Colorado, USA, pp. 154-165, 2003. Available: https://doi.org/10.1109/ISSRE.2003.1251039

[247] I. M. P. Pratistha, N. Nicoloudis, and S. Cuce, "A Micro-Services Framework on Mobile Devices," Proceedings of the International Conference on Web Services 2003, Las Vegas, NV, United States, 2003.

[248] Elsevier, What is the complete list of Scopus Subject Areas and All Science Journal Classification Codes (ASJC)? Available: https://service.elsevier.com/app/answers/detail/a_id/15181/supporthub/scopus/. Accessed on July 21, 2021.

[249] D. Staegemann, M. Volk, N. Jamous, and K. Turowski, "Exploring the Applicability of Test Driven Development in the Big Data Domain," Proceedings of the ACIS 2020, Wellington, New Zealand, 2020. 